\title{
Transient Fault Detection and Location in Power Distribution Network: A Review of Current Practices and Challenges in Malaysia
}

\author{
Saidatul Habsah Asman ${ }^{1, * \mathbb{C}}$, Nur Fadilah Ab Aziz ${ }^{1}$, Ungku Anisa Ungku Amirulddin ${ }^{1}$ (D) \\ and Mohd Zainal Abidin Ab Kadir ${ }^{2}$ D \\ 1 Institute of Power Engineering (IPE), Universiti Tenaga Nasional, Jalan IKRAM-UNITEN, \\ Kajang 43000, Selangor, Malaysia; nfadilah@uniten.edu.my (N.F.A.A.); anisa@uniten.edu.my (U.A.U.A.) \\ 2 Advanced Lightning, Power and Energy Research (ALPER), Universiti Putra Malaysia, \\ Serdang 43400, Selangor, Malaysia; mzk@upm.edu.my \\ * Correspondence: saidatul.habsah@uniten.edu.my
}

Citation: Asman, S.H.; Ab Aziz, N.F.; Ungku Amirulddin, U.A.; Ab Kadir, M.Z.A. Transient Fault Detection and Location in Power Distribution Network: A Review of Current Practices and Challenges in Malaysia. Energies 2021, 14, 2988. https:// doi.org/10.3390/en14112988

Academic Editor: Hugo Morais

Received: 22 March 2021

Accepted: 12 May 2021

Published: 21 May 2021

Publisher's Note: MDPI stays neutral with regard to jurisdictional claims in published maps and institutional affiliations.

Copyright: (c) 2021 by the authors. Licensee MDPI, Basel, Switzerland. This article is an open access article distributed under the terms and conditions of the Creative Commons Attribution (CC BY) license (https:// creativecommons.org/licenses/by/ $4.0 /)$.

\begin{abstract}
An auto-restoration tool to minimize the impact of faults is one of the critical requirements in a power distribution system. A fault-monitoring system is needed for practical remote supervision to identify faults and reduce their impacts, and thus reduce economic losses. An effective faultmonitoring system is beneficial to improve the reliability of a protection system when faults evolve. Therefore, fault monitoring could play an important role in enhancing the safety standards of systems. Among the various fault occurrences, the transient fault is a prominent cause in Malaysia power systems but gains less attention due to its ability of self-clearance, although sometimes it unnecessarily triggers the operation of protection systems. However, the transient fault is an issue that must be addressed based on its effect that can lead to outages and short-circuits if prolonged. In this study, the authors summarize the guidelines and related standards of fault interaction associated with a monitoring system. The necessity of transient fault detection and location techniques and their limitations, the need for signal processing, as well as recommended practices, are also discussed in this paper. Some of the practices from local power utility are also shared, indicating the current approaches, key challenges, and the opportunities for improvement of fault-monitoring systems due to transient fault, which can be correlated with the reviews provided.
\end{abstract}

Keywords: power distribution system; fault detection; fault location; fault-monitoring system; transient fault

\section{Introduction}

A monitoring system usually involves managing an electrical power network for the purposes of controlling and protecting the entire network. The system visualizes the status of the network and predicts future potential failures. The most essential part of monitoring is to maintain an uninterrupted power supply in order to reduce power outage time caused by faults [1,2]. Since the late 1990s, the Malaysian electricity supply company Tenaga Nasional Berhad (TNB) has installed numerous types of fault recorders in several substations to monitor critical overhead transmission lines. However, none have been installed in the distribution feeders. The monitoring system in a distribution system (DS) is dependent on a circuit breaker and relay trip in the substation based on conventional techniques [3,4]. As a counterpart to the transmission line, the DS is constructed of tapped lateral networks or branches that deliver power to the consumers. The monitoring of faults in the DS is more complex due to this convoluted construction [5-7]. The branches are exposed to various types of faults caused by several sources including climatic conditions, equipment failure, and natural phenomena. Figure 1 illustrates a power system with connected parties including generators, a grid system, and a distribution system in Malaysia. As of December 
2018, 47\% power plants in Peninsular Malaysia consisted of gas power plants, 38\% coal, $9 \%$ hydroelectric, and $1 \%$ diesel power plants, while the remaining $5 \%$ were renewable energy included large-scale solar, mini hydro, and industrial waste heat. Upon this value, 23,082 km of transmission lines and cables that included $500 \mathrm{kV}, 275 \mathrm{kV}$, and $132 \mathrm{kV}$ voltage system are utilized to distribute power supply into 443 transmission substations. Then, 113,469 GWh of power supply was then distributed to 9.039 million customers through overhead distribution lines and underground cables.

In a distribution system, utility companies attempt to maintain the availability performance of the distribution grid in line with world-class standards. The distribution grid performance indicators are based on the minimum outage cost, utility travel cost, and System Average Interruption Duration Index (SAIDI) [8-10]. SAIDI is an indication of the number of interruption hours that an average consumer will experience annually. A lower SAIDI value indicates less unexpected interruption duration and a more reliable system. Figure 2 presents a comparison of distribution SAIDI for several countries in 2017. From the bar chart, the most reliable distribution performance was in Singapore with a SAIDI of $0.56 \mathrm{~min} /$ consumer/year, while the highest SAIDI value was for Paris with 61.10 $\mathrm{min} /$ consumer/year, which indicates the least reliable system. Malaysia recorded a SAIDI of $50.24 \mathrm{~min} /$ consumer/year, which is considered to indicate low reliability of the distribution grid [8]. Singapore's high-reliability system performance is attributed to its efficiency of maintenance and installation of underground cables, which enhances the reliability and security of the electrical network. These factors were the most significant in the Malaysian distribution grid due to the complex infrastructure and congestion of underground utilities services. Among distribution performance in Malaysia, Putrajaya state recorded the most reliable distribution performance with the SAIDI of $0.73 \mathrm{~min} /$ consumer/year. Meanwhile, Pulau Pinang recorded the highest number of interruptions in the state with the SAIDI $78.66 \mathrm{~min} /$ consumer/year as shown in Figure 3.

With regard to the high level of interruption occurrences, it is vital for the DS to be efficient in managing faults and maintaining the quality of service by reducing the outage time $[1,11]$. In particular, the increase in distributed generation (DG) linked to the grid affects the power quality and causes substantial problems for the existing fault detection and location methods [12]. Various improvements have been made by researchers to expedite fault location $[13,14]$ and an attempt has been made to define the fault location measure to explain the reliability of a fault monitoring system at an accurate location $[15,16]$. Fault monitoring defined as a process encompasses detecting, diagnosis, isolating, and sometimes repairing malfunctioning components in the DS [17]. To sustain the reliability of energy supply to consumers, the DS needs to pursue certain standards that involve control and operation, reporting of outages and interruptions, monitoring of performance, and co-ordination of safety. Table 1 presents the recommended standards related to fault monitoring in a DS system [18]. The standards comprise measuring and recording of voltage magnitude variations, fast voltage changes, supply voltage sags, brief interruptions of supply voltage, transients, supply voltage unbalance, and harmonic voltage [9,19-25]. Further, the combination of computing and modern wireless communication techniques allows for prolific intelligent monitoring in real time and efficient control of distribution systems within smart grid frameworks $[26,27]$. Therefore, these standards enable the performance of best practice in terms of communication, data transfer, and security measures [9,28-32] for Malaysian DS.

One of the crucial monitoring operations in a distribution system is fault detection and location. Fault detection is a process of judging whether or not the fault occurs by comparing the optimal value parameters with the measured valued exceeded threshold value set up [33]. Various approaches have been adopted to detect and locate faults in a DS, without focusing on transient faults. The transient fault gains lack of concern due to its self-clearance but has a high potential to cause a short-circuit. Furthermore, in certain situations, the transient fault could be propagated through the cable while transmitting the power supply. In consequence, a power quality issue is initiated, thus reducing the 
DS performances. Due to the limited study focusing on transient fault, there are no specific methods employed to detect transient faults in the Malaysian distribution system. Previously, conventional methods based on visual inspection were adopted to detect the fault. The approach was time-consuming and required an expert engineer to process the fault where it may cause more damages to the system. Since then, various automatic fault detection methods were introduced to overcome the problems. In this paper, most of the techniques developed and commonly used to detect and locate faults in DS associated with transient disturbance are reviewed. The working principles, advantages, disadvantages, and other past works related to each technique are described and compared. Hence, from this review, the opportunities in fault detection and location research areas in power distribution systems can be explored further.

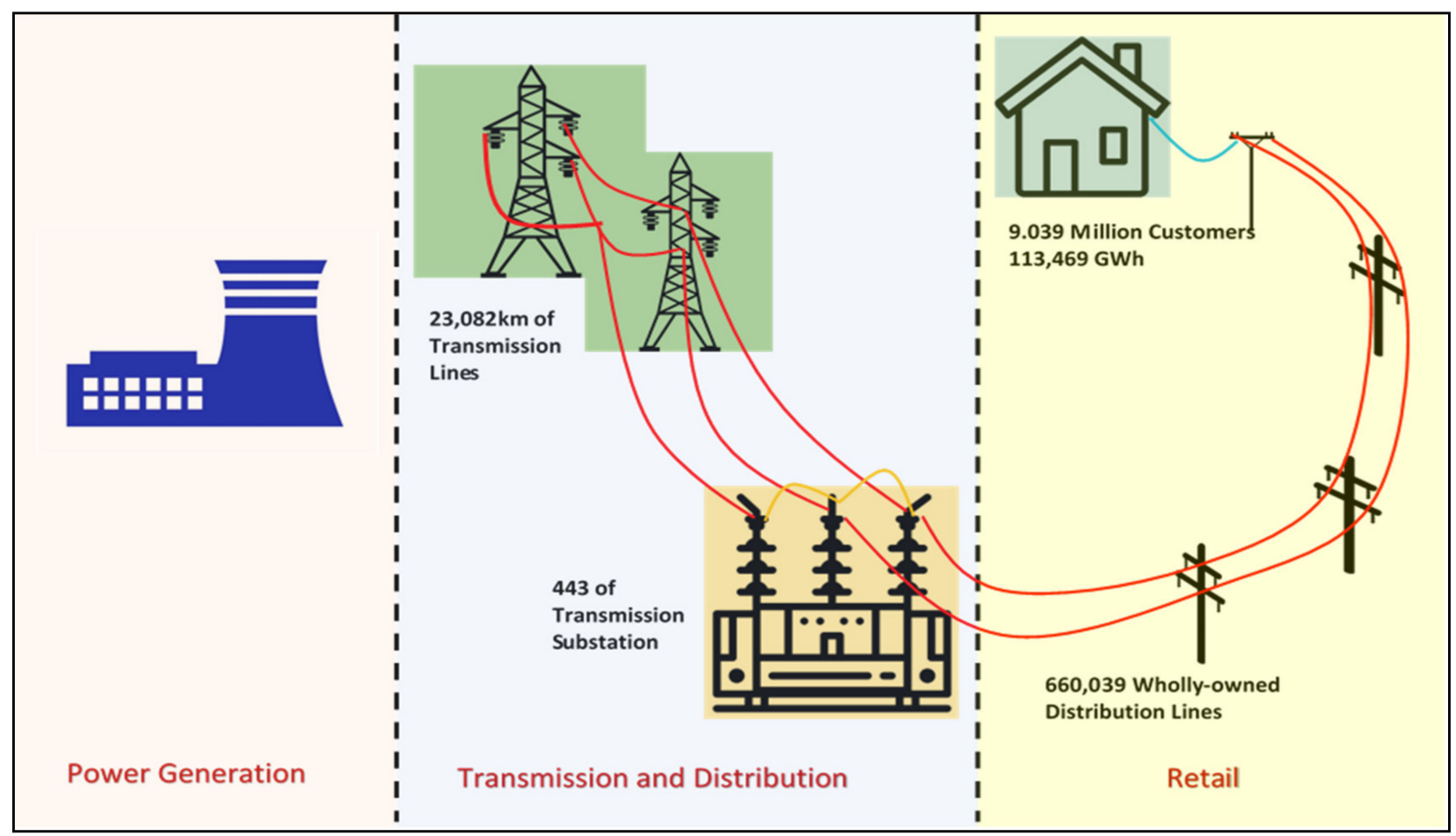

Figure 1. Power system connected parties [34].

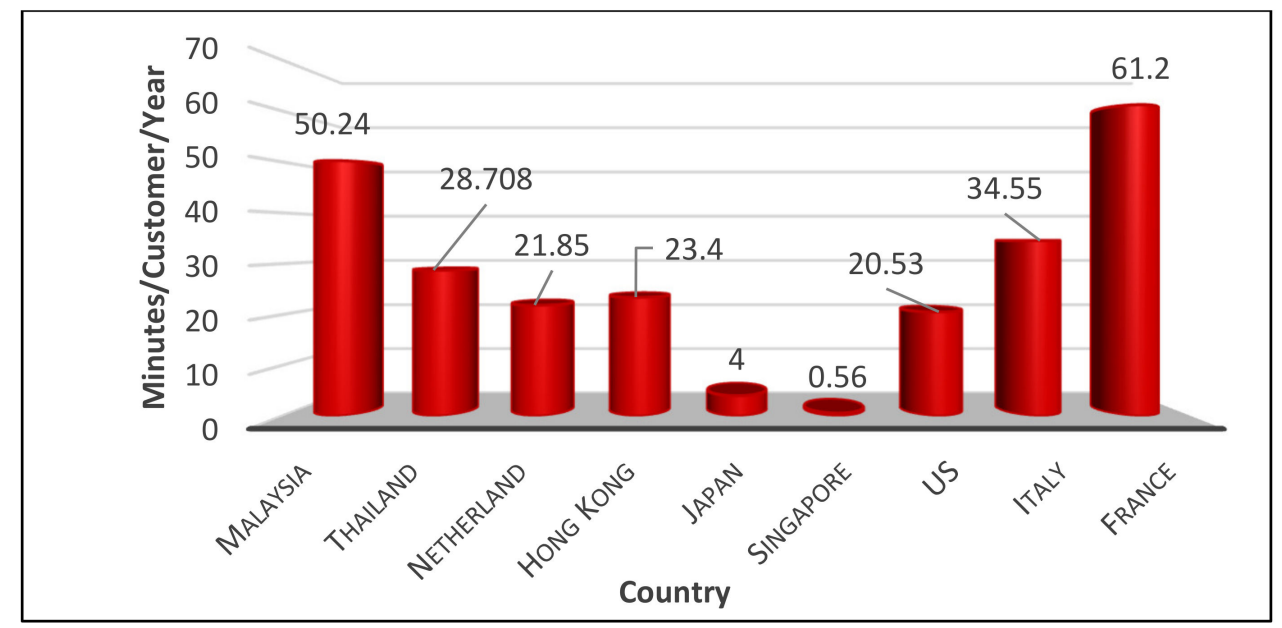

Figure 2. SAIDI performance of distribution system for Malaysia and various cities around the world [8,35]. 


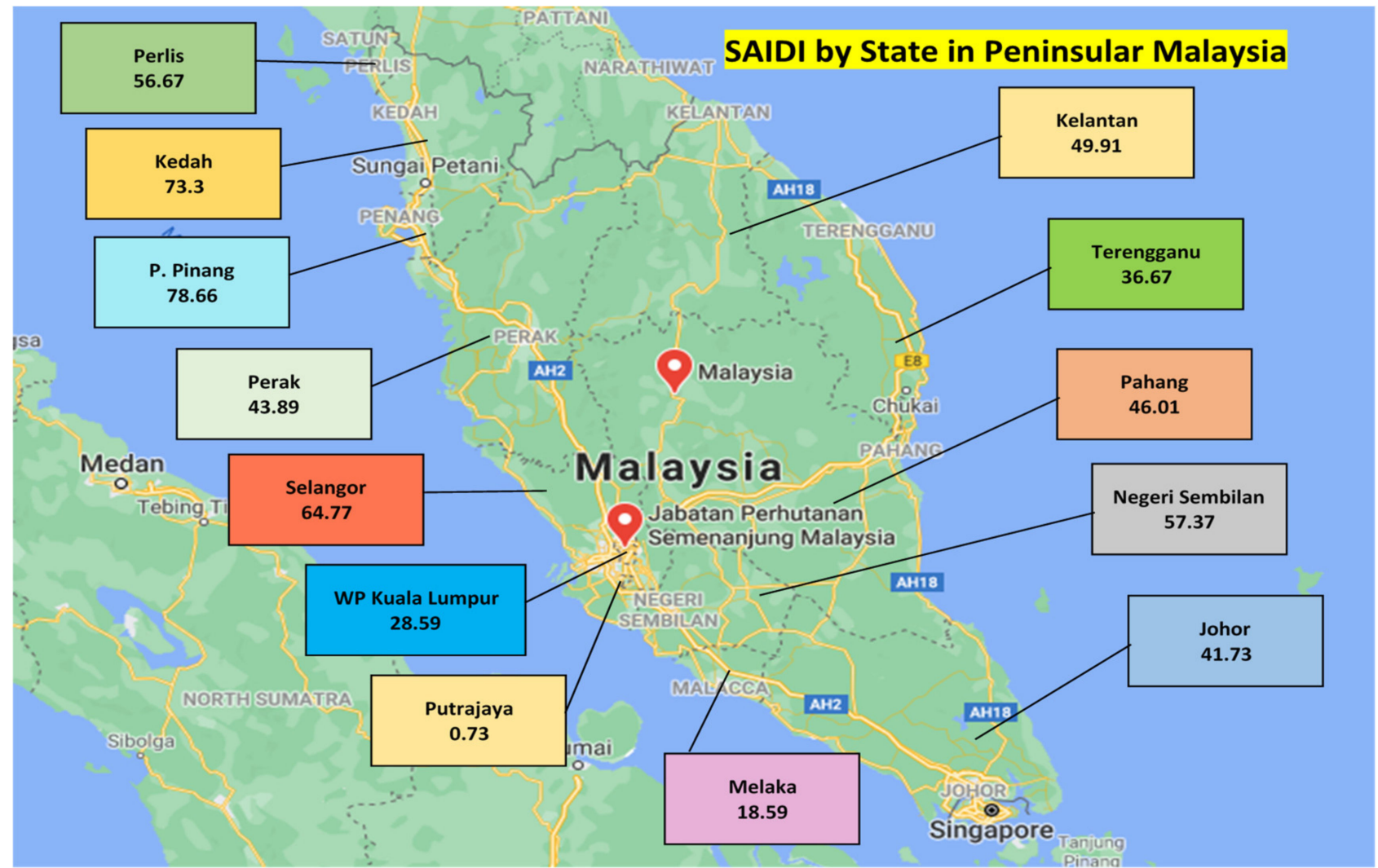

Figure 3. SAIDI by state in Peninsular Malaysia in 2017.

Table 1. Recommended standard for fault monitoring.

\begin{tabular}{|c|c|c|c|}
\hline Standard & Title & Outline & Description \\
\hline IEC Standard 60909 [9] & $\begin{array}{l}\text { Short-circuit currents in } \\
\text { three-phase A.C. Systems }\end{array}$ & Calculation & $\begin{array}{l}\text { Maximum and minimum } \\
\text { prospective short-circuit } \\
\text { currents in a system for every } \\
\text { specific location and time }\end{array}$ \\
\hline IEC Standard 61000-3-6 [19] & $\begin{array}{l}\text { "Assessment of emission } \\
\text { limits for distorting loads in } \\
\text { MV and HV power systems" }\end{array}$ & Installation & $\begin{array}{l}\text { Emission limit for harmonic } \\
\text { emission in MV }\end{array}$ \\
\hline IEC Standard 61000-3-7 [20] & $\begin{array}{l}\text { "Assessment of emission } \\
\text { limits for fluctuating loads in } \\
\text { MV and HV power systems" }\end{array}$ & Installation & $\begin{array}{l}\text { Chapter 8: "Emission limits } \\
\text { for fluctuating installations } \\
\text { connected to MV systems" }\end{array}$ \\
\hline IEEE-1159 [21] & $\begin{array}{c}\text { "Recommended Practice for } \\
\text { Monitoring Electric Power } \\
\text { Quality" }\end{array}$ & Measuring and recording & $\begin{array}{l}\text { Chapter 5: "Monitoring } \\
\text { objectives" }\end{array}$ \\
\hline IEEE Std C37.114 ${ }^{\mathrm{TM}}-2014$ [22] & $\begin{array}{c}\text { "Guide for Determining Fault } \\
\text { Location on AC Transmission } \\
\text { and } \\
\text { Distribution Lines" }\end{array}$ & Measuring and recording & $\begin{array}{l}\text { Chapter 5: "Other Fault } \\
\text { Location Application" }\end{array}$ \\
\hline IEEE Std C37.011 & $\begin{array}{c}\text { "Guide for the Application of } \\
\text { Transient recovery Voltage for } \\
\text { AC High Voltage Circuit } \\
\text { Breakers" }\end{array}$ & Procedure and calculation & $\begin{array}{l}\text { Chapter 3: "Transient } \\
\text { Recovery Voltage" }\end{array}$ \\
\hline
\end{tabular}


Table 1. Cont.

\begin{tabular}{|c|c|c|c|}
\hline Standard & Title & Outline & Description \\
\hline IEEE Std 1894 ${ }^{\mathrm{TM}}-2015$ [36] & $\begin{array}{l}\text { "Guide for Online Monitoring } \\
\text { and Recording Systems for } \\
\text { Transient Overvoltages in } \\
\text { Electric Power Systems" }\end{array}$ & Measuring and recording & $\begin{array}{c}\text { Chapter 4: "The configuration } \\
\text { and functions of online } \\
\text { monitoring and recording } \\
\text { systems for transient } \\
\text { overvoltages in power } \\
\text { systems" }\end{array}$ \\
\hline
\end{tabular}

\begin{tabular}{|c|c|c|c|}
\hline IEEE Std 1729 ${ }^{\mathrm{TM}}-2014$ [24] & $\begin{array}{c}\text { "Recommended Practice for } \\
\text { Electric Power Distribution } \\
\text { System } \\
\text { Analysis" }\end{array}$ & Model Design & $\begin{array}{c}\text { Chapter } 4: \text { "Recommendation } \\
\text { for test feeder" }\end{array}$ \\
\hline IEEE Std 551M-2006 [37] & $\begin{array}{l}\text { "Calculating Short-Circuit } \\
\text { Currents in Industrial and } \\
\text { Commercial Power Systems" }\end{array}$ & Calculation & $\begin{array}{l}\text { Chapter 12: "Short-circuit } \\
\text { calculations under } \\
\text { international standards" }\end{array}$ \\
\hline IEEE Std 399-1997 [25] & $\begin{array}{l}\text { "Recommended Practice for } \\
\text { Industrial and } \\
\text { CommercialPower Systems } \\
\text { Analysis" }\end{array}$ & Measuring and recording & $\begin{array}{l}\text { Chapter 11: "Switching } \\
\text { Transient Studies" }\end{array}$ \\
\hline IEC 61850 [9] & "Standard for SCADA" & Communication and Design & $\begin{array}{c}\text { Lecturer 5: "Standard for the } \\
\text { design of substation } \\
\text { automation" }\end{array}$ \\
\hline IEEE 802.15.4 [28] & $\begin{array}{l}\text { "Standard for Low-Rate } \\
\text { Wireless Networks" }\end{array}$ & $\begin{array}{l}\text { Communication and } \\
\text { installation }\end{array}$ & $\begin{array}{c}\text { Chapter 5.2.1: "Smart Utility } \\
\text { network" }\end{array}$ \\
\hline IEC 62351-7 [29] & $\begin{array}{l}\text { "Communication and } \\
\text { Information Management } \\
\text { Technologies" }\end{array}$ & Security Measures & $\begin{array}{c}\text { Part 7: Security Through } \\
\text { Network and System } \\
\text { Management }\end{array}$ \\
\hline IEC 60870-5 [30] & "Telecontrol Function" & Communication & $\begin{array}{l}\text { Part 5: Communication profile } \\
\text { for sending basic telecontrol } \\
\text { messages between two } \\
\text { systems, which use } \\
\text { permanent directly connected } \\
\text { data circuits between the } \\
\text { systems. }\end{array}$ \\
\hline $\begin{array}{l}\text { IEC 60255-24:2013 and IEEE } \\
\quad \text { Std C37.111-2013 [31] }\end{array}$ & $\begin{array}{l}\text { "Measuring Relay and } \\
\text { Protection Equipment" }\end{array}$ & Data Exchange & $\begin{array}{l}\text { Part 24: Common format for } \\
\text { transient data exchange } \\
\text { (COMTRADE) for power } \\
\text { systems }\end{array}$ \\
\hline ANSI C12-19-2012 [32] & $\begin{array}{c}\text { "Utility Industry End Device } \\
\text { Data Tables" }\end{array}$ & Application data & $\begin{array}{c}\text { Part 19: Table structure for } \\
\text { utility application data to be } \\
\text { passed between an Device and } \\
\text { any other device }\end{array}$ \\
\hline
\end{tabular}

This paper is organized as follows: A brief explanation of the fault categories and their description is presented in Section 2. General fault types focusing on unbalanced faults with basic principles are discussed in Section 3. In Section 4, the transient fault classes and their protection systems are provided, including the general protection system and specific lightning protection. Section 5 reviews the existing conventional fault detection and processing methods, which encompass travelling wave-based and impedance-based methods. The working principles of each method with advantages and limitations are discussed. Moreover, artificial intelligence and signal processing methods that have been developed to date are also reviewed. Section 6 provides a summary of the reviewed study, challenges to be encountered, and recommendations for future methods anticipated to be appropriate for the Malaysian system. Lastly, Section 7 concludes various fault detection and location approaches that have been developed with their advantages and limitations. 


\section{Fault Categories}

A fault in a distribution system can be categorized as either a permanent or a temporary fault that causes the system to deviate from its standard operating procedure [38-41].

\subsection{Temporary Fault}

A temporary fault in an electrical system is difficult to identify since it rarely results in a blown fuse and there is no available evidence of the cause or location of the fault. In a distribution system, auto reclosers (ARs) are widely used to enable the elimination of temporary faults. Although a temporary fault is self-clearing, frequent operation of ARs can cause disruption to the generator system, thus reducing the energy delivered to the network. In addition, temporary self-clearing has become an item of concern since it affects sensitive customer loads such as adjustable speed motor drives that can reduce the quality of power supplied $[39,42]$. A temporary fault is usually due to transient phenomena in the distribution system.

\subsection{Permanent Fault}

When a permanent fault occurs, protective relay equipment makes it possible for the associated circuit breaker to de-energize the faulty section. The fault would be first interrupted by the recloser-fast operation, followed by inrush. Then, the recloser interrupts the fault again by a second recloser fast operation and two recloser slow operations. The last slow operation finally clears the fault [43]. The load connected will not be supplied if the faulty lines are not maintained. Consequently, the line may trip and can cause sustained outage of large power systems [44]. There are several factors that may cause a permanent fault, such as insulation cable failure, an object falling on the overhead line, and the line falling to the ground.

\section{Unbalanced Fault in Power Distribution System}

There are two types of faults associated with overhead line distribution systems that may lead to a temporary or permanent fault. The types are a balanced fault and an unbalanced fault. The most frequent faults that occur are the unbalanced fault. The unbalance fault can be categorized into series and shunt faults.

\subsection{Series Fault}

A series fault is an abnormality at which the impedances of the three phases are not equal, usually caused by the interruption of one or two phases [45]. The series fault represents an open-circuit fault. Changes in the current in an open circuit are very low, which is different from short-circuits. Series faults are characterized by an increase in voltage and frequency and a decrease in current in the faulted phase. The open-circuit fault usually does not cause the system to shut down but will affect its performance $[46,47]$.

\subsection{Shunt Fault}

Under a shunt fault, there is a flow of current between two or more phases, or between a phase and ground. Shunt faults are characterized by an increase in current and a decrease in voltage and frequency. The shunt fault can be divided into single-line-to-ground fault (SLGF), line-to-line fault (LLF), double-line-to-ground fault (DLGF), and three-phases-toground fault (LLLGF). The most common faults that occur in overhead lines are SLGF and DLGF, which are usually caused by lightning, wind, or falling trees. About 70\% of faults that occur are classified as SLGF, which are also known as short-circuit faults, while $20 \%$ of the faults are classified as DLGF [45]. The LLLGF is categorized as a balanced fault whereby it is very rare for it to occur compared to the other faults. However, this fault is the most dangerous and is usually caused by a falling tower where the line is connected to the tower structure. 


\section{Transient Faults in Malaysia}

Most of the shunt faults that cause temporary and permanent faults are vulnerable to transient interruption. Transient occurrences can be random, and vary in degree depending on the operating environment at the time of occurrence [48,49]. Table 2 and the figures below present the statistics of power system performance in Malaysia to indicate its vulnerability to the various fault causes including transient. In the last eleven years (2008 to 2018), Malaysia has recorded an average of 78,404 unscheduled interruptions throughout the year [50-60]. Table 2 shows the percentage of unscheduled interruptions by fault causes in the Malaysian distribution system. From the table, the highest percentage of fault causes was due to process and quality work that could be categorized into loose contact, improper maintenance, and overloading. The least number of fault causes percentage belongs to natural disasters, with an average value of $0.32 \%$. The natural disaster can be categorized into flood, wind, and landslide. Meanwhile, the faults caused by other events recorded interruption percentages at an average of $1.82 \%$. Other classes were categorized as insulation ageing, short-circuit, encroachment, relay malfunction, and transient. Figure 4 illustrates a bar chart of the percentage of fault causes to display a clearer comparison value. From the bar chart, it shows that other fault causes (including transient fault) recorded the highest percentage in 2017, which rose by $98 \%$ from the previous years. Simultaneously, the number of interruptions from year 2014 to 2018 is presented by the states in Malaysia as shown in Figure 5. Overall, Selangor state shows the highest number of interruptions in 2018 with 15,132 occurrences in comparison with others state. Meanwhile, Putrajaya shows the least number of interruptions with only 14 occurrences compared to the other states. Statistically, transients are well-known for the least number of occurrences in comparison to harmonics.

Transient faults in a power system are usually addressed as unplanned events, which are commonly caused by lightning strikes or switching phenomenon. The fault is usually represented as a temporary fault and it garners little concern, in comparison with a permanent fault, due to its self-clearing nature and the fact that it does not affect the restoration operation. However, if prolonged, the fault may cause outages and short-circuit faults [61,62]. Accordingly, short-circuit waveforms consist of transient signals, and excess current surges through the system could cause the breakdown of several system components because of the extreme heat generated [63]. In addition, some challenging and interesting issues are created, such as the precise modeling of the power system at heightened frequencies and the characterization of determined transient occurrences [64-67].

Table 2. Percentage of unscheduled electricity supply interruptions by fault causes (excluding high voltage interruptions) in Peninsular Malaysia [52-62].

\begin{tabular}{|c|c|c|c|c|c|c|c|c|c|c|c|}
\hline \multirow{2}{*}{ Fault Causes } & \multicolumn{11}{|c|}{ Year and Percent $(\%)$} \\
\hline & 2008 & 2009 & 2010 & 2011 & 2012 & 2013 & 2014 & 2015 & 2016 & 2017 & 2018 \\
\hline $\begin{array}{l}\text { Process and } \\
\text { quality work }\end{array}$ & 47.1 & 54.78 & 57.6 & 44.94 & 46.22 & 48.28 & 47.58 & 48.44 & 50.76 & 43.82 & 44.11 \\
\hline Equipment & 2.7 & 2.3 & 2 & 31.44 & 30.95 & 31.41 & 34.08 & 29.7 & 29.43 & 25.46 & 39.19 \\
\hline Tree & 8.7 & 11.96 & 10.6 & 14.86 & 14.29 & 13.46 & 10.75 & 12.32 & 10.99 & 12.12 & 10.02 \\
\hline $\begin{array}{l}\text { Third party } \\
\text { Damage }\end{array}$ & 15.7 & 1.98 & 2.2 & 5.7 & 5.19 & 4.87 & 5.15 & 5.84 & 5.95 & 5.58 & 5.42 \\
\hline Natural Disaster & 0.1 & 0.19 & 0.2 & 0.48 & 0.54 & 0.26 & 0.44 & 0.6 & 0.36 & 0.28 & 0.16 \\
\hline $\begin{array}{l}\text { Others (include } \\
\text { transient) }\end{array}$ & 3 & 2.63 & 1.8 & 0.15 & 0.73 & 0.25 & 0.27 & 0.35 & 0.22 & 10.42 & 0.17 \\
\hline Vandalism & $\mathrm{N} / \mathrm{A}^{*}$ & 12.6 & 10.9 & 0.55 & 0.43 & 0.47 & 0.62 & 0.83 & 0.7 & 1.42 & 0.29 \\
\hline Animal & $\mathrm{N} / \mathrm{A}^{*}$ & $\mathrm{~N} / \mathrm{A}^{*}$ & $\mathrm{~N} / \mathrm{A}^{*}$ & 1.88 & 1.65 & 1 & 1.11 & 1.92 & 1.59 & 0.9 & 0.64 \\
\hline Unknown & 22.7 & 13.58 & 14.7 & $\mathrm{~N} / \mathrm{A} *$ & $\mathrm{~N} / \mathrm{A}^{*}$ & $\mathrm{~N} / \mathrm{A} *$ & $\mathrm{~N} / \mathrm{A}$ * & $\mathrm{N} / \mathrm{A}^{*}$ & $\mathrm{~N} / \mathrm{A}^{*}$ & $\mathrm{~N} / \mathrm{A}^{*}$ & $\mathrm{~N} / \mathrm{A}$ * \\
\hline
\end{tabular}




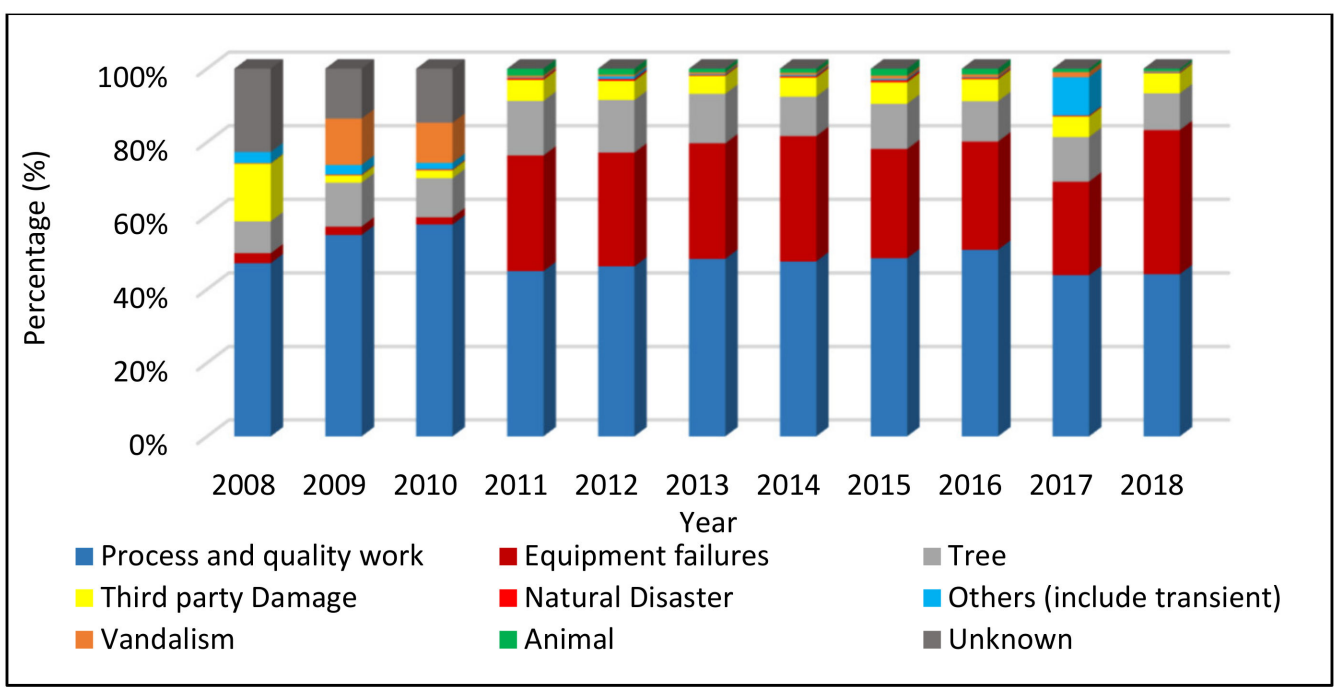

Figure 4. Bar chart of fault causes interruptions in Peninsular Malaysia from 2008 to 2018 [50-60].

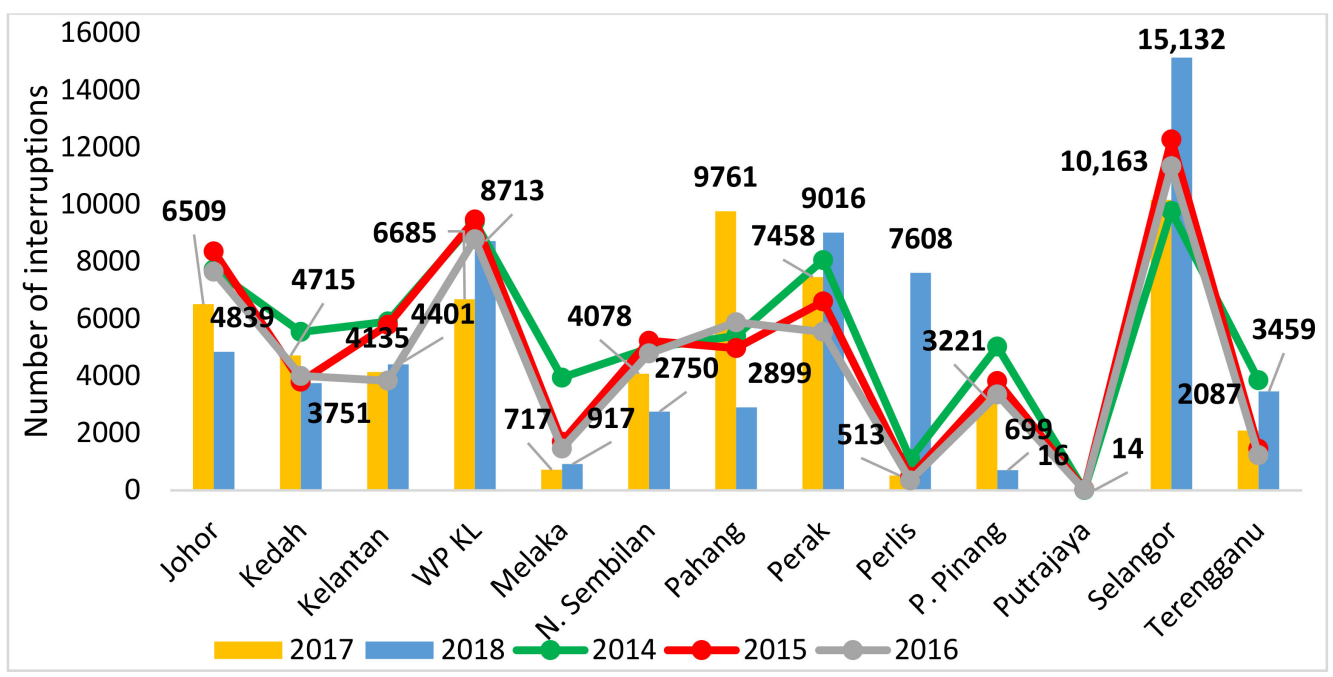

Figure 5. Number of interruptions by state in Peninsular Malaysia from 2014 to 2018 [56-60].

\subsection{Transient Classes}

Two transient classes exist, namely the "impulsive transient" and the "oscillatory transient." The first is defined as "a sudden frequency change in the steady-state condition of voltage, current, or both that is unidirectional in polarity" while the second is defined as "a natural transient in the electric power system" that dominates the impulsive transient [64]. The typical duration of a transient phenomenon is dependent on the spectral content of the transient itself as defined by IEEE-1159 [68]. Table 3 describe the characteristics of transient classes in DS based on event categories. Meanwhile, the description of transient causes in a distribution system is shown in Table 4.

\subsubsection{Impulsive Transient}

Impulsive transients, generated by various sources such as lightning, switching, and a broken conductor (high impedance fault), are the most frequent events in an overhead line distribution system. They have their own features and are increasingly used to prevent prolonged impact. However, impulsive transients due to lightning have been found to be the main reason for recurrent interruptions and tripping in the Malaysian distribution system, which is the concern of this study. This is due to Malaysia being near the equator, with extreme lightning activity of about 200 thunderstorms daily [69-73]. The extent of 
the rise in the frequency of faults caused by lightning strikes is a significant factor to be considered when installing substation insulation and determining the appropriate strategy to limit this overvoltage. The lightning flashes can cause disturbances and faults in a power system if they exceed the limitation of the regulatory standard. Consequently, the power quality indices in such a system are degraded. Based on all lightning discharge types, the cloud-to-ground (CG) discharge is the most dangerous to humans, and in addition, electrical equipment can be severely damaged. Most CG discharges occur sequentially as separate return strokes with a current amplitude ranging between a few $\mathrm{kA}$ to more than $200 \mathrm{kA}$, which is considered to be very high [74-79].

Table 3. Characteristics of transient phenomena.

\begin{tabular}{|c|c|c|c|c|}
\hline Category & Event-Based Classification & $\begin{array}{c}\text { Typical Spectral } \\
\text { Content }\end{array}$ & Typical Duration & $\begin{array}{c}\text { Typical Voltage } \\
\text { Magnitude }\end{array}$ \\
\hline $\begin{array}{l}\text { Impulsive } \\
\text { Nanosecond } \\
\text { Microsecond } \\
\text { Millisecond }\end{array}$ & Lightning & $\begin{array}{c}5 \mathrm{~ns} \text { rise } \\
1 \mu \mathrm{s} \text { rise } \\
0.1 \mathrm{~ms} \text { rise }\end{array}$ & $\begin{array}{l}<5 \mathrm{~ns} \\
50 \mathrm{~ns} \text { to } 1 \mathrm{~ms} \\
>1 \mathrm{~ms}\end{array}$ & \\
\hline $\begin{array}{l}\text { Oscillatory } \\
\text { Low frequency } \\
\text { Medium frequency } \\
\text { High frequency }\end{array}$ & $\begin{array}{ll} & \text { Capacitor energizing } \\
\text { - } & \text { Restrike during capacitor } \\
\text { deenergizing } \\
\text { - } \quad \text { Line or cable energizing }\end{array}$ & $\begin{array}{c}\quad<5 \mathrm{kHz} \\
5 \text { to } 500 \mathrm{kHz} \\
0.5 \text { to } 5 \mathrm{MHz}\end{array}$ & $\begin{array}{c}0.3 \text { to } 50 \mathrm{~ms} \\
20 \mu \mathrm{s} \\
5 \mu \mathrm{s}\end{array}$ & $\begin{array}{l}0 \text { to } 4 \mathrm{pu} \\
0 \text { to } 8 \mathrm{pu} \\
0 \text { to } 4 \mathrm{pu}\end{array}$ \\
\hline
\end{tabular}

\subsubsection{Oscillatory Transient}

An oscillatory transient is defined as a non-power frequency change in a steadystate condition. The oscillatory behavior is intimately linked to a nonlinear property derived from a mathematical definition [80]. The condition is either in terms of voltage or current that includes both negative and positive polarity values. Oscillatory transients are characterized by magnitude, duration, and spectral content. These interruptions are normally due to energization during the switching of a capacitor bank [81,82].

\subsection{Transient Fault Protection System}

A protection system comprises several components such as voltage and current transformers, protective relays, circuit breakers, and communication channels [83]. The main purposes of transformer protection are based on a satisfyingly fast and reliable relay to isolate the power transformer from the grid with minimum damage. Avoiding maloperation of the protection system during different operating conditions is also another role of the power transformer. Several studies have been conducted to protect power transformers such as voltage measurement due to a short circuit between two different voltage levels, a description of a current signal using wavelets and a correlation coefficient, the current and voltage ratio at the primary and secondary terminal, and an instantaneouscurrent-value negative sequence differential element [3,84-86].

A protective relay is ideally used to detect a problem during the initial stage and eliminate possible damage to equipment. The protective relay is associated with a circuit breaker functioning to trip a breaker when a fault is detected. The fault detection scheme consists of a relay that detects a fault in one of two power system zones separated by a circuit breaker and initiates tripping of that circuit breaker. However, it does not represent the fault detector function of breaker failure $[87,88]$.

In terms of communication medium, utilities are dependent on supervisory control and data acquisition (SCADA). Fault operation is integrated using SCADA and impacts of faults on distribution systems have been broadly determined by researchers [89-91]. When a fault occurs on the feeder, the normal system protection will isolate the feeder from the source. The process involves isolation and restoration to return the system back to normal. SCADA requires a separate operator to travel to the affected feeder and verify the next action. This process is time consuming and could affect other consumers. 
Figure 6 illustrates the SCADA configuration for a TNB control center in an electrical substation. A device master Request-To-Send (RTS) transmits the signal parameters obtained from the digital fault recorder at the measurement points. The parameters are then transmitted to the central station. Once a fault occurs, signals can be monitored simultaneously using computer software. A SCADA system will monitor using coded signals to control the protection devices such as relays, IEDs, and transformers.

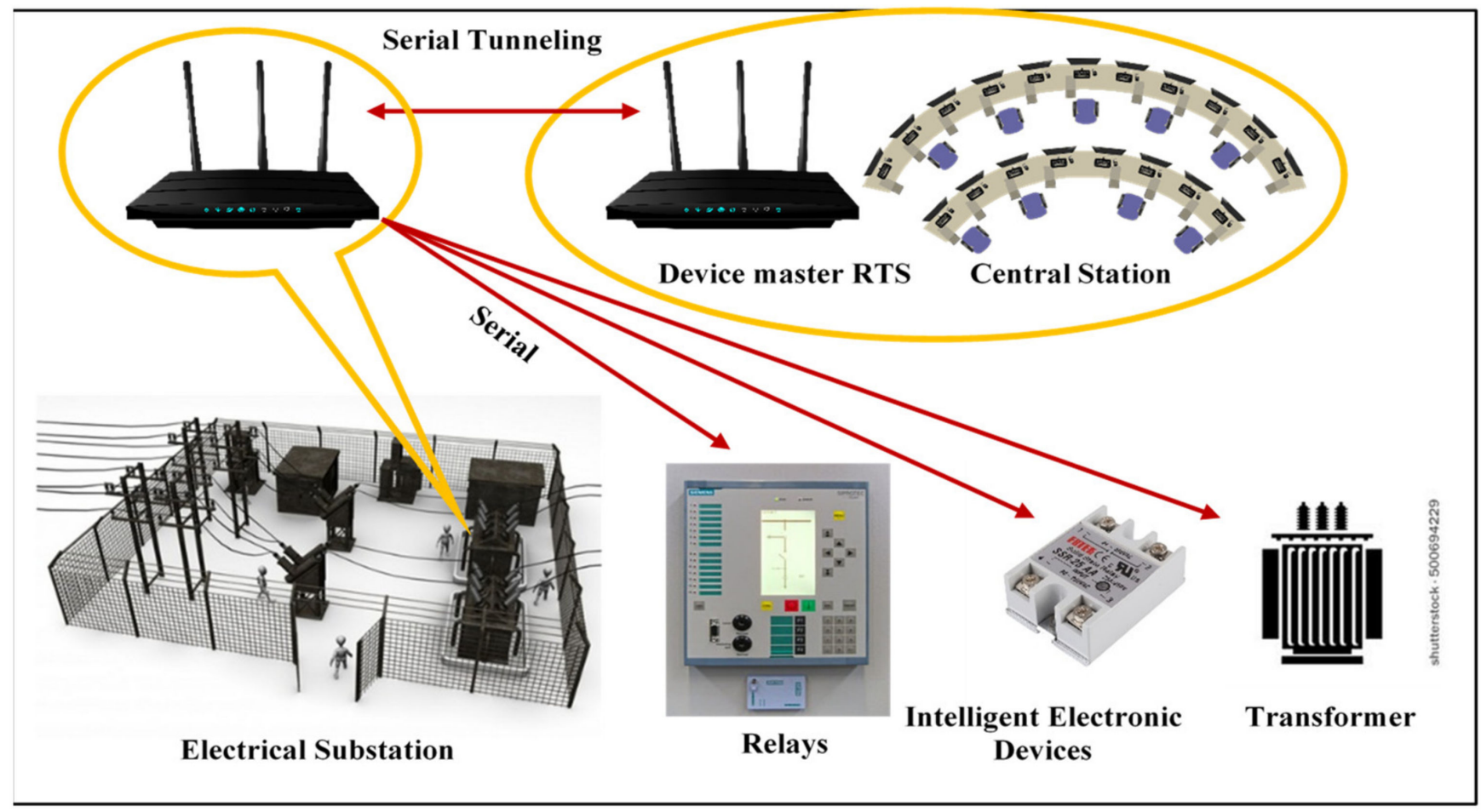

Figure 6. SCADA configuration for TNB control center in an electrical substation [87].

Nevertheless, the general protection system is quite different from a lightning event protection system. A lightning overvoltage may cause flashover along the overhead line as well as insulation failure in cables and equipment. Some effective ways to reduce the flashover rate on overhead line distribution networks could be by installing a surge arrester, upgrading the line insulation, and adding a shield wire. The protective devices usually contain one non-linear element such as a Metal Oxide (MO) surge arrester, capacitors, or old silicon carbide $(\mathrm{SiC})$ to limit the transient overvoltage and divert the surge current. All these motivations for the protection of overhead lines is to minimize the incidence of short interruptions and voltage sag due to flashovers from lightning [92,93]. In order to select the correct lightning protection system, identification of the lightning flash parameters is required. These parameters include:

- The shape of the lightning current-peak value, front time, tail time, and duration.

- Polarity.

- Multiplicity of number of components in a flash.

To evaluate the insulation efficiency of electric power equipment, a standard lightning impulse, with a wave front/tail time of $1.2 / 50 \mu \mathrm{s}$, is stipulated by the IEC Standard in the impulse voltage withstand tests [94-97]. Based on IEC 62350-1 Ed. 2 [98,99], the lightning current estimation of the first return stroke is shown in Figure 7. From the graph, $I_{0}$ represents the current peak value, $t_{0}$ is the front time, $t_{1}$ is the time to $10 \%$ of peak value, $t_{2}$ is the time to $90 \%$ of peak value, $t_{\mathrm{h}}$ is the total time to half value of the peak (tail time), $t_{\max }$ is the time to the peak value, $\mathrm{T}_{1}$ is the front duration, and $\mathrm{T}_{2}$ is (virtual) time to half value [94]. 
Table 4. Description of transient causes in distribution systems.

\begin{tabular}{|c|c|}
\hline Event & Description \\
\hline $\begin{array}{c}\text { Capacitor switching } \\
{[21,36,63-65]}\end{array}$ & $\begin{array}{l}\text { - } \quad \text { Capacitor used in DS to enhance the power factor and to lower line loses. } \\
\text { - } \quad \text { Voltage rises due to switching is } 1.5 \text { to } 2 \text { times of the nominal voltage. } \\
\text { action may lead to overlapping transients. } \\
\text { - Transient voltage magnified due to switching must not exceed } 2 \text { p.u which is considered a safe } \\
\text { condition. }\end{array}$ \\
\hline Lightning [67-73,97-99] & $\begin{array}{l}\text { - } \quad \text { Extreme lightning activity in Malaysia. } \\
\text { - } \quad \text { Could damage appliances and reduce lifetime of electrical equipment. } \\
\text { - } \quad \text { Amount of energy contained is very strong and causes overvoltage. } \\
\text { - Necessary to install lightning arrester. }\end{array}$ \\
\hline $\begin{array}{l}\text { High Impedance } \\
\text { Fault [100-106] }\end{array}$ & $\begin{array}{l}\text { - Due to live conductor feeder breaking and coming into physical contact with surfaces such as } \\
\text { leaves, stone or sand. } \\
\text { - Voltage magnitude becomes lower thus producing low current close to the load current level. } \\
\text { - Leads to being non-detectable by the protection system such as relays and fuses. }\end{array}$ \\
\hline
\end{tabular}

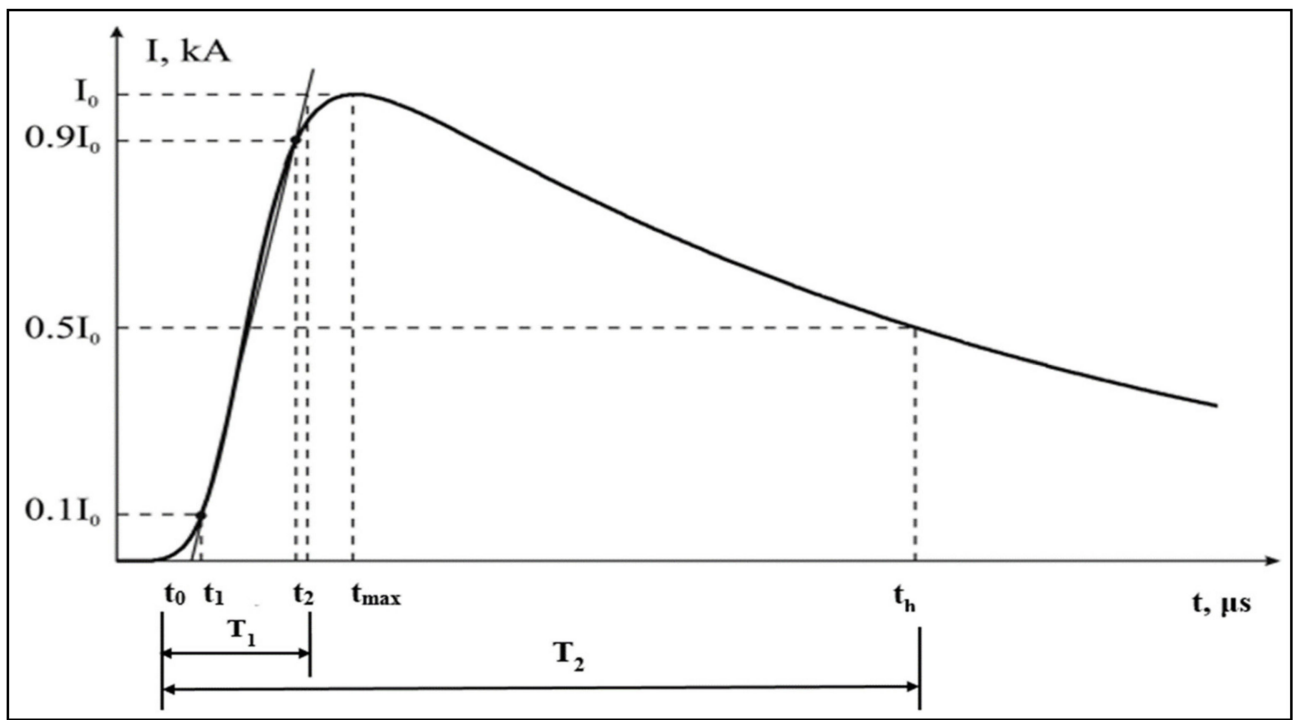

Figure 7. Lightning current approximation by Heidler function [93].

\section{Methods and Processes to Detect Transient Faults}

Power distribution systems experience fault occurrences. Therefore, to ensure uninterrupted power supply, there is a need to isolate faulty lines from the system. Note that the diagnosis of faults requires enough information to determine the possible causes of the problem before proceeding with the detection process [107]. The information can be collected from several sources and different layers of the network. Several methods have been suggested by researchers to detect and locate faults based on the fault current, voltage level, and short-circuit location. Since transient fault occurrences in Malaysia are limited, this section will explain some general fault detection methods that applicable to transient fault. Sections 5.1 and 5.2 explained conventional and contemporary detection methods respectively, while Section 5.3 explained signal processing methods before undergoing the detection process. 


\subsection{Conventional Methods}

Previously, conventional methods such as travelling wave (TW) and impedance-based methods have been proposed to detect and locate faults.

\subsubsection{Travelling Wave Method}

The travelling wave (TW) technique, also referred to as a high-frequency electromagnetic impulse, is propagated along the lines in both directions away from the fault point at almost the speed of light $[7,108]$. The system generally employs the transient signals generated by the fault as the main study [5-7]. The system needs very high data acquisition, a high speed flashing rate, a Global Positioning System (GPS), and a transient detector device, but the TW has a lack of capability to sense low-amplitude faults such as a "conductor in the snow" [109]. Precise time is the main element of system success in obtaining an accurate fault location. The fault location determination for a travelling wave has its basis in the arrival time-tag at both ends of the line and making a comparison of the time difference to the total propagation time of the line [108]. Figure 8 illustrates the basic travelling wave scheme in a transmission network.

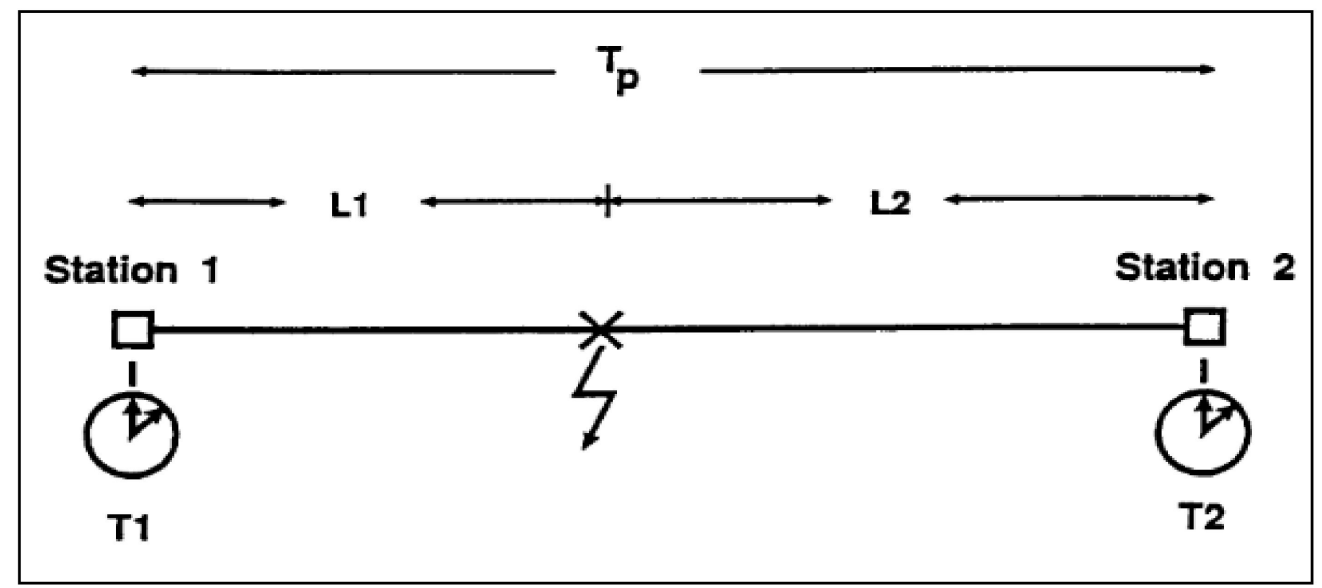

Figure 8. Travelling wave scheme in a transmission network [108].

The distance of the fault from the line terminals is given by (1):

$$
L_{2}=\frac{T_{p}+\Delta T}{2} \times V_{p} \text { and } L_{1}=\frac{T_{p}-\Delta T}{2} \times V_{p}
$$

where $V_{p}$ is the velocity of propagation for the line, and $\Delta T=T_{2}-T_{1}$.

TW methods can be classified into single-terminal and two-terminal fault location approaches. The two-terminal method proceeds by acquiring data from both ends of the feeder compared to the single terminal, which acquires data at only one end of the feeder [110]. TW methods are mostly implemented in transmission line networks. However, there are several studies that have applied the methods in DS such as in [111], while some studies of single-terminal fault location have worked on radial DS [110,112]. The majority of fault location studies have been based on time-frequency analysis by determining reflected fault fronts of fault points using the wave velocity of zero mode components. Consequently, the fault can be located, and information can obtained such as various fault starting angles, voltage level, fault phase, fault starting angle, and fault resistance. However, this approach is complex.

From the above, it can be noted that TW methods are able to detect and locate the faults in a DS. However, implementation is very costly since it involves the use of many devices and produces a variation of travelling waves (inconsistent) especially for the single-terminal fault procedure [113]. However, this application has been tested for the Malaysias DS based on the integration of SCADA, Remote Terminal Unit (RTUs), and 
Power Line Communication (PLC) system as detector components [90]. The proposed study could be a reference to explore the casualties of transient fault. The DS also consists of a complex configuration involving several branch networks, which make the application of the method difficult. Table 5 summarizes the reviewed TW implementations. Most of the studies focus on a one-ended terminal to trace the transient faults. The common fault type occurring on an overhead line is SLGF. The fault resistance and inception angle parameters indicate that they influence the accuracy in finding the location of the fault. High fault resistance lowers the capability of the approach in locating the faulty section. Further, the existence of DG also affects the exactness of the fault distance.

\subsubsection{Impedance Based Method}

Currently, the impedance-based technique involves estimating the distance of a fault by using impedance information from a substation, which have been implemented in the Malaysian DS [114-117]. The voltages and current values are the main parameters in implementing this method [112]. A faulty circuit can be analyzed in the phase or sequence domain [118-122]. In contrast to the transmission line, distribution characteristics typically have several loads whereas the voltage and current magnitudes are obtained from the substation. The faulty sections can be investigated using simulation or a load flow study, which is proposed in reference [120], which used (2) to locate the nearest node to the fault location. The $j$ th node with the greatest index value is defined as "the one with the least mismatch between the calculated voltage sags $\left(\Delta V_{i, j}^{c}\right)$ and measured voltage sags $\left(\Delta V_{i}^{m}\right)$, and would be the closest node to the real fault location".

$$
\text { index }_{j}=\frac{1}{\sum_{i=1}^{m}\left|\Delta V_{i}^{m}-\Delta V_{i, j}^{c}\right|+\varepsilon}
$$

where $m$ is the number of voltage meters and $\varepsilon$ is a small value to avoid a zero denominator.

Table 5. Fault location using the travelling wave method.

\begin{tabular}{|c|c|c|c|c|c|c|c|}
\hline \multirow{2}{*}{ Ref. } & \multirow{2}{*}{ Terminal } & Network & Parameters & Fault Types & Source of Fault & \multirow{2}{*}{ Ref. } & \multirow{2}{*}{ Terminal } \\
\hline & & TL & RDS & Fault Resistance $(\Omega)$ & Inception Angle $\left({ }^{\circ}\right)$ & & \\
\hline$[112]$ & One & & $\checkmark$ & 10 to 300 & $\mathrm{~N} / \mathrm{A}^{*}$ & SLGF & $\mathrm{N} / \mathrm{A} *$ \\
\hline [110] & One & & $\checkmark$ & 1 to 30 & $\mathrm{~N} / \mathrm{A} *$ & SLGF & Transient \\
\hline$[123]$ & Double and Multi & & $\checkmark$ & 0.1 to 300 & 10 to 90 & SLGF & Transient \\
\hline [124] & Two & $\checkmark$ & & 10 & 0 & SLGF & $\mathrm{N} / \mathrm{A}^{*}$ \\
\hline [125] & One & $\checkmark$ & & $\mathrm{N} / \mathrm{A} *$ & $\mathrm{~N} / \mathrm{A}$ * & SLGF & Transient \\
\hline
\end{tabular}

* N/A: Information not available in the reference paper.

The index value calculated from (2) for all node networks will find the nearest fault location and based on the index value, the fault location will be defined as upstream or downstream from the node as indicated in [118]. The higher the index value, the closer the fault distance will be to the node. Different methods have been found to verify the location of a fault by considering all fault types including SLGF, LLF, LLGF, and LLLGF. For example, the impedance-based method used in [118] is suitable for a tapped transmission line, which uses only voltages and currents to obtain the impedance value. The proposed method is applied on the tapped line that has an outcome maximum error of less than $3 \%$. All fault types based on symmetrical components can be tested and the fault successfully detected and located. From the review, the impedance-based method is extensively utilized due to its low cost and simplicity. In addition, it requires low measurement parameters, thus providing advantages for practicable implementation. On the other hand, this method typically results in inaccurate fault location for a single fault due to the combination of the load, fault resistance, and equivalent impedances of the power system. 


\subsection{Data-Driven Methods}

The data-driven method is proposed as an alternative with less online computation for identifying fault detection and location compared to conventional methods [11,45]. This contemporary method requires information such as feeder measurement, substation and feeder switch status, fault information from devices, and atmospheric condition. The data-driven approach, such as artificial intelligence (AI), impersonates a biological neural network of the brain, which processes the information by training and testing the system. AI can be defined as "the automation of activities associated with human thinking such as learning from examples, perceptions, decision making and problem solving" [126]. The methods have the ability to represent complex input and output. The input typically comprises measured voltage and current while the output is the fault distance. AI approaches that have been used to detect and locate faults include:

- Artificial Neural Network (ANN) including:

- Convolutional Neural Network (CNN).

- $\quad$ Long Term and Short Term Memory Network (LSTM).

- Fuzzy Logic.

- $\quad$ Support Vector Machine (SVM).

- Genetic Algorithm.

\subsubsection{Artificial Neural Network}

The Artificial Neural Network (ANN) is among the most common tools of AI because it is considered to be a universal function approximator, it can be implemented in parallel with concurrent architectures, and, most importantly, it can be trained by backpropagation [127]. The ANN known as machine learning does not require a knowledge-based network, as instead it has to be trained with numerous cases. The ANN consists of neurons that are linked to several architectural layers [128] such as illustrated in Figure 9. Various researchers have adopted a signal processing-based ANN approach to detect faults. The signal processing type wavelet transform (WT) is employed in studies to retrieve features of a faulty branch and fault distance. A statistical feature such as standard deviation is used to find the faulty branch while skewness is adopted to find the fault distance. The features are then used as input data for the ANN to classify the fault [129-132].

The advantages of the ANN method are fast computation and simplicity. However, the ANN suffers from drawbacks as it requires a high amount of data to produce a highquality training and testing system. Further, trial-and-error cases are used to identify some parameters such as hidden layers, neurons, and the learning rate in order to acquire optimal results [45]. Additionally, the ANN needs a large amount of input data information, which is difficult to obtain from the fault information of a DS. Large samples will cause the ANN to overfit and reduce the computational time $[133,134]$.

In a meantime, the requirements of ANN become more powerful, complex, and literally deeper with many layers and neurons, thus a deep learning is introduced to achieve machine learning objectives. With an advance in the new generation of artificial intelligence (AI 2.0), Convolutional Neural Network (CNN) is introduced to overcome the drawbacks of ANN. The CNN is capable to analyzed multi-channel signals over the existing deep learning method. In [135], the authors implemented CNN, which combines the properties of deep learning, transfer learning, and ensemble learning to perform the rotating machinery fault detection. In [136], the authors proposed an advance $\mathrm{CNN}$, which improved the flow of information over the network known as densely connected CNNs (DCNNs) to detect bearing faults. The DCNNs require fewer unknown parameters than the conventional $\mathrm{CNN}$ and can refrain from redundant representation. 


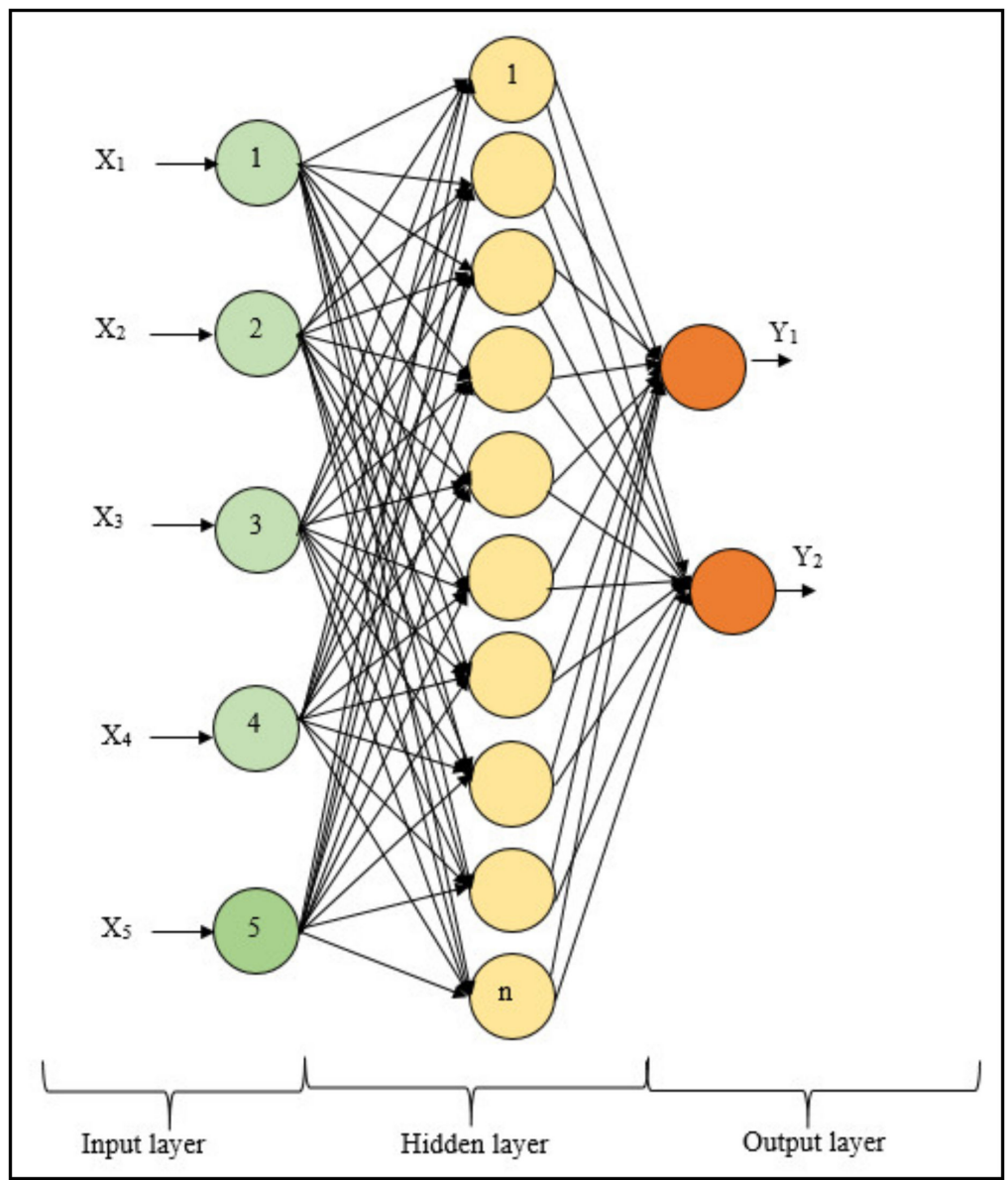

Figure 9. Architecture of neural network.

In the power system distribution network integrated with DGs, the CNN was implemented for the first time by Rai et al. to detect and locate a fault [137]. According to the study, the proposed model achieved $99.52 \%$ accuracy performance with less trainable parameters in comparison with the conventional machine learning method. Instead of a raw signal, image detection based on CNNs has been further studied by Xusheng et al. [138]. The authors proposed a CNN based on Faster R-CNN to deal with the massive image fault causes due to insulator damage and bird nests on the high voltage lines. From the reviewed study, the $\mathrm{CNN}$ is concluded to be an effective tool to locate faults with the minimum pre-trained data with high accuracy of testing data. However, the proposed methods were found to be very computationally effective during the online mode but computationally expensive when trained in the offline mode. Furthermore, the CNN was incapable of detecting complex features since it only learns to detect simple features. This is very crucial whenever it comes to detecting images that have specific coordinate elements.

Since the CNN is a particular form of an ANN with a feedback loop storing recent input as an activation input, it suffers from the limitation of vanishing and exploding. Therefore, a long-term and short-term memory network (LSTM)-based gated cell was introduced to overcome the CNN drawbacks. The LSTM comprises three gates, namely the forget gate, input gate, and output gate [139]. In particular, the LSTM networks learns what to memorize and when to allow reading/writing during the training. However, the LSTM consumes much training time since the number of hidden layers increases [140,141]. In DS, the LSTM application has been adopted to detect HIF in a solar PV integrated system and outperformed the accuracy value in comparison with SVM [139]. Meanwhile, Abdelazeem et al. adopted LSTM to detect islanding, incorporating it with an inverter in the microgrid. Furthermore, Ling et al. proposed the hybridization of a $\mathrm{CNN}$ and the long-term and shortterm memory network (LSTM) to detect the complex changeable working environment 
in a wind turbine [140]. The LSTM can better affiliate with the characteristics that have a great impact on output variables in order to improve the accuracy of the model. It is worth mentioning that although the robustness of the CNN and the LSTM were proven experimentally, the methods have never been found to be used to detect any faults in the Malaysian DS, which has become an opportunity for future research.

\subsubsection{Fuzzy Logic}

Fuzzy logic is defined as "a type of AI used in classifying the source of fuzzy logic". Fuzzy logic theory has its basis in the domain where its activities or observations are vague or ill-defined. In fact, fuzzy sets are developed, but do not comprise well-described or definite boundaries of activities such as it does not determine as a 'true-false' or numerical ' $1-0$ ' description. Although the fuzzy logic is famous for its simplicity and ease in designing the algorithm, it suffers from difficulties in determining the right set of rules and membership function if the system complexity increases. Generally, the fuzzy rules and membership function are generated based on system behavior learned by the neural net using input and output data [142]. Figure 10 illustrates an example of membership function generated by the Fuzzy Rule Generator based on the input given. The fuzzy concept has been suggested to recognize fault detection and location accuracy in low-voltage (LV) networks [143-148]. For example, reference [143] adopted density over the number of consumer units (D) and the ratio between the number of smart consumer devices and the total number of consumers (SM/CT) as factors to mark out and localize a fault. This technique has the advantage of being able to independently determine fault location along the line length. However, the number of smart meter (SM) devices should be increased with the increase of line length, which requires high cost to implement [149]. In addition, in TL, a fault location identification and classification system based on a directional relay using a fuzzy logic system has been proposed [149]. The phase angle of positive sequence current information has been employed to determine the direction of a fault within half a cycle and this scheme has worked well in many fault case studies.

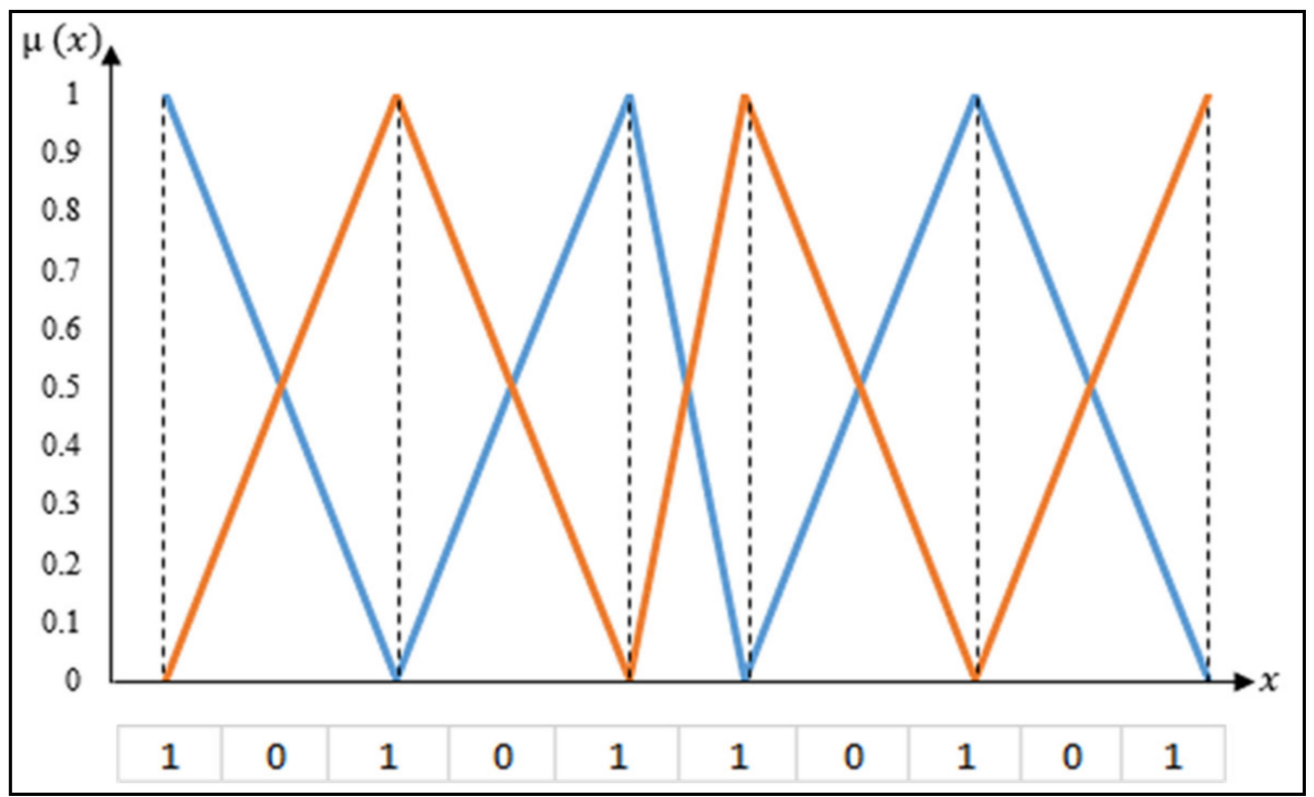

Figure 10. Membership function of fuzzy logic.

Fault detection using the fuzzy method has also been proposed for Photovoltaic (PV) protection [150]. The voltage ratio (VR) and power ratio (PR) were applied as input data for an ANN to categorize the fault region in examining the PV. Then, the second technique was implemented to detect the exact fault in the PV system. The centroid type for the defuzzification process was chosen, and 10 different membership functions were 
considered for the fuzzy logic process. In [151], the author proposed a Fuzzy Causeand-effect network (FCE) in a DS for fault diagnosis. In the study, fault diagnosis used to identify inappropriate functioning components thus reducing maintenance cost and downtime equipment [152]. The measurement of feeder currents and bus voltage derived from SCADA was converted into fuzzy terms before it was specified into membership functions of fuzzy sets. Instead of fault diagnosis, fuzzy logic has also been applied for the identification of the fault type. From the review, fuzzy logic is an easier method in comparison with the ANN because it requires no training. Therefore, the computation burden would be significantly decreased with a correspondingly lower computation time. Further, fuzzy requires a reduced data set to obtain an output compared to the ANN, which needs a large training data set for the learning process.

\subsubsection{Support Vector Machine}

The Support Vector Machine (SVM) technique is based on the Vapid Chervonenkis (VC) dimension, which is used in pattern recognition problems, and is given by the maximum number of points that can be separated by the function class [153]. Figure 11 shows the structure of an SVM. Computational output weight in the SVM network depends on input random weight and bias $\left(W_{n}\right.$ and $\left.b\right)$ of hidden nodes, which is not fixed. The SVM has the capability to solve high-dimensional pattern recognition, nonlinear, and small-sample problems due to its high ability to obtain the best compromise between the complexity of the models and learning capability on the basis of finite sample information. SVM lowers the classification error and increases the geometric margin on the basis of Structural Risk Minimization (SRM). It maps the input vector into a higher-dimensional space where a maximal separating hyper plane is built to separate the classes with the constraint of increasing the distance between the separating hyper planes. The transformation of the hyperplane separating the mapping space was generated by kernel function. The kernel function has parameters to be optimized known as regularization parameters $C$ and $\gamma$. The types of kernel function should be chosen appropriately to judge the most prudent input data.

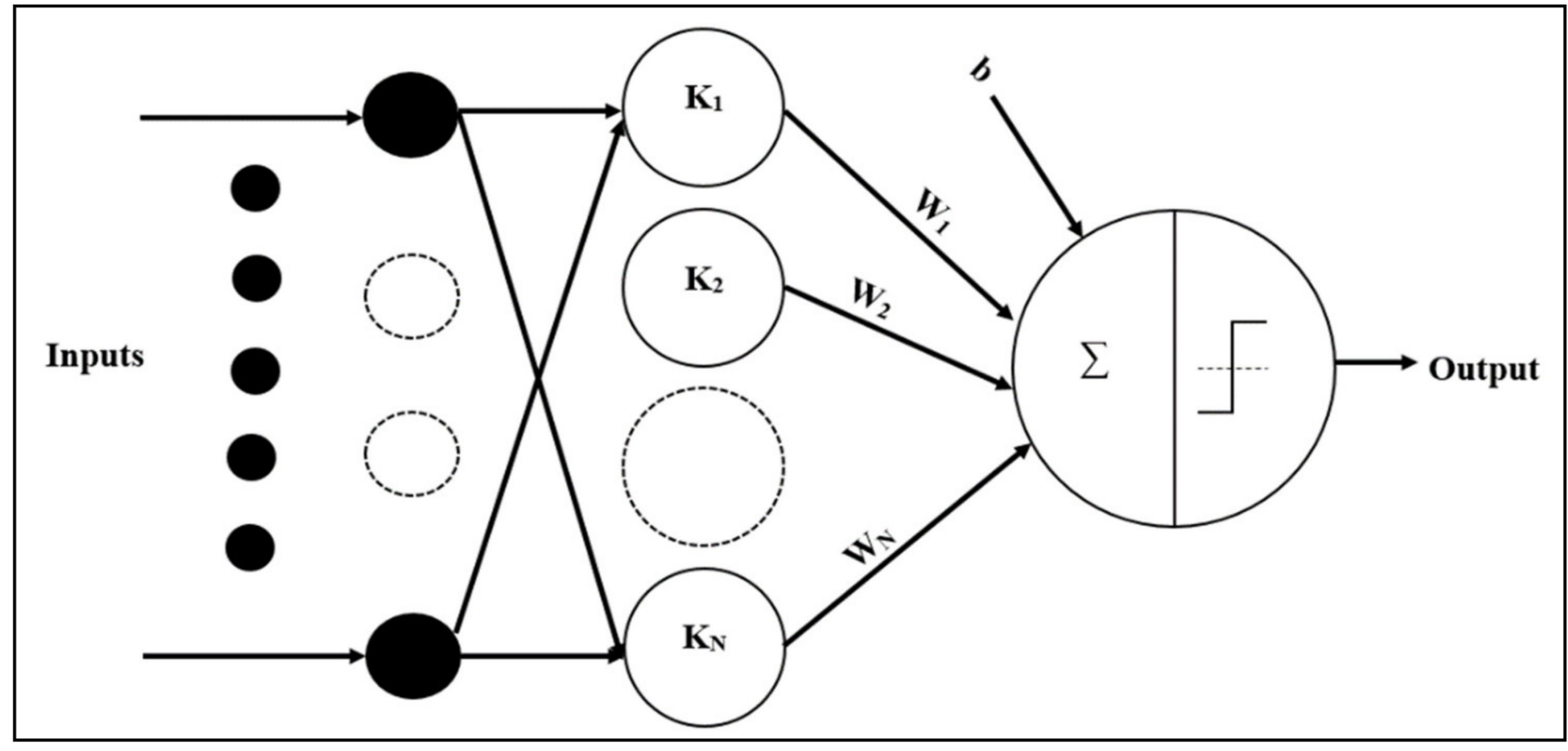

Figure 11. The structure of SVM [153].

The SVM-based algorithm is widely used for fault type classification and fault location identification in transmission and DS based on feature parameters extracted such as voltage, current, and frequency variations [128,154-158]. For example, in [159], authors proposed 
fault identification and classification using SVM in Malaysian DS application. The algorithm was tested on IEEE 34 and IEEE 123 bus system by varies the gamma parameter in SVM to find an optimal accuracy value. Another study that adopted SVM in Malaysian utilities was that proposed by Zahriyah and Rubiyah [160]. However, the research focused on detecting incipient faults in a power transformer instead of the distribution line network. Research has found that the best features are necessary for the prediction of the fault location, in which the optimization process can then be implemented [161]. The advantages of SVM include its fast learning speed and small sample demand. The major characteristic of SVM is the non-dependence of the upper bound on the generalization error on the dimension of the space. By maximizing the margin, the error bound can be reduced. Therefore, choosing SVM to locate the fault is a great idea based on its advantages.

\subsection{Features Optimization}

The optimization process is a different stage before the data are classified in a Neural Network (NN). An efficient NN classifier obligates an optimizer to classify large-dimension datasets and solve the optimization problem. The optimization process is a part of features selection due to its role to estimate an unavoidable useless information. In this sense, the optimization procedure will mainly optimize high-dimensional features by searching for the most significant information of the evaluated condition. This section provides the optimization algorithm deployed for data reduction.

\section{Genetic Algorithm}

Genetic Algorithms (GAs) are defined as "the family of computational models inspired by evolution or mimic of natural evolution" [162-165]. In other words, the GAs find a solution using a local search technique by producing successive populations until it obtains an acceptable result $[166,167]$. The results are represented by chromosomes and the procedures are known as fitness function. The evolution of GAs is illustrated in Figure 12 while the main procedures are introduced by three main definitions:

- Selection: The process where the solutions should be preserved (allowed) or deserve decay. The best solution will be selected, and others will be discarded. Here, fitness function and optimality will be quantified.

- Crossover: A new solution is created from existing available solutions after the selection process.

- Mutation: Introducing of novel features into the solution to preserve the population diversity.

GAs and Mallow's Cp have been proposed to place Power Quality Monitors (PQMs) in order to detect and locate a fault [134]. Multivariate Regression (MVR) is adopted to obtain the maximum and minimum voltage deviations to find the exact voltage sag-source. In short, GAs can be implemented to find the optimal location to place the monitoring device and not to find the source of the voltage sag. The techniques are impractical and expensive since the PQMs need to be installed at various places. In some cases, GAs were adopted to determine an optimal parameter of NN. For example, in [168], the GA was adopted by Moloi et al. to improve the performance of the NN classifier in order to classify between faulty and healthy phases. In [148], GA was implemented based on the measured voltage over dispersed generation (DG). The GA was adopted to find the optimal solution with an unknown fault location and fault resistance variables by measuring the voltage sag source at the DG terminal. However, the accuracy of the proposed method was low with an average error of $5.73 \%$. In addition, Haghifam et al. discriminated HIF from transients using a GA-based method in the DS [168]. Although there are numerous transient faults that occur in the distribution, the adoption of the GA to detect the fault is still limited and has not been thoroughly explored by the researchers. To conclude, the GA is mainly used as a classifier to optimize and enhance the performance efficiency of the AI. 


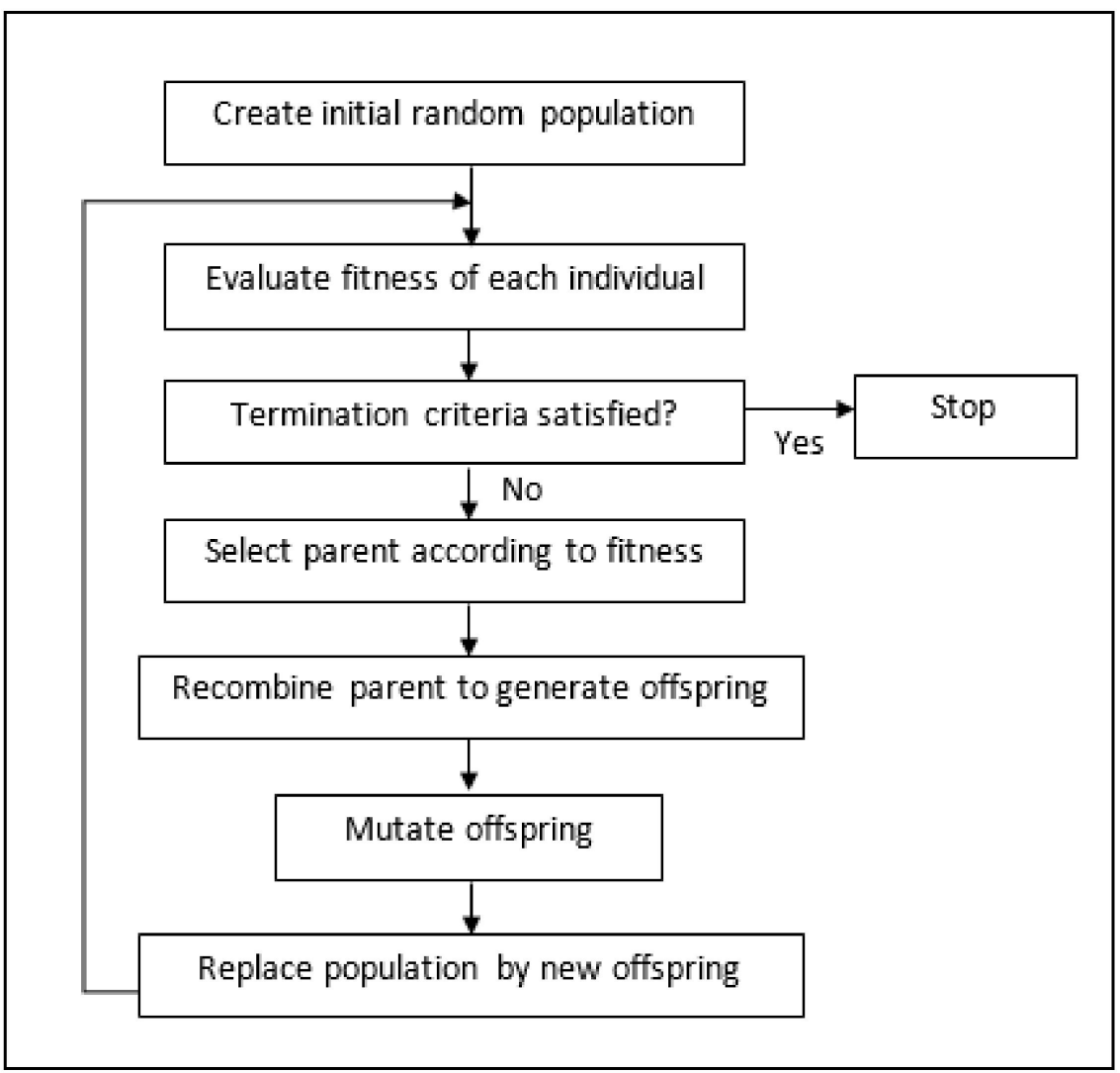

Figure 12. GAs evolutionary algorithm.

\subsection{Signal Processing Methods}

Data pre-processing is a prior step that must not be neglected before going through the fault detection process. Data pre-processing, also known as signal processing, is significant to clean noise signal and determine many missing values created by the sensor [169]. Neglecting the cleaning process could result in an unreliable signal and a false alarm. Another purpose of data pre-processing is to normalize the data including it scaling and weighting to ensure the layer can easily learn the input data, thus accelerating the training process [170]. Furthermore, the pre-processing data are applied to reduce the dimension of data [171]. The most common method used for reducing the dimension of data is Principal Component Analysis (PCA). After the pre-processing step, the data should be processed to extract and select the features using signal processing methods [172,173]. The most frequent signal processing methods adopted in the fault detection process are the wavelet transform (WT), Stockwell Transform, and Empirical Mode Decomposition (EMD).

\subsubsection{Wavelet Transform}

The wavelet transform (WT) is an appropriate method to be applied to a wide-band signal that is non-periodic such as typical transients. It has the capability to focus on short time intervals for high-frequency components and long intervals for low-frequency components, thus improving the analysis of signals with localized impulses and oscillations [174]. In the literature, the WT has been used for feature extraction, data compression, and de-noising of a transient disturbance [175].

The Wavelet Transform is a very useful technique to analyze a transient phenomenon. Multiresolution analysis (MRA) for time and frequency is one of the tools of WT. The wavelet algorithm decomposes a non-stationary signal into a low-frequency signal called approximation and a high-frequency signal called details [115,176-178]. The disturbance waveforms are decomposed using WT at the desired level ' $j$ ' with various types of wavelet families. The decomposition of the signal into various frequency bands is achieved by 
applying a high-pass filter and a low-pass filter to the time domain signals. The most common WT reviewed was the discrete wavelet transform (DWT), which has been widely used to discriminate fault type, fault location, fault resistance, and variation of power flow angle [179-184]. In addition, another fast detection technique of disturbances was revealed based on DWT and the Second-Generation Wavelet Transform (SGWT) [185]. The experimental evaluation compared the faster detection of disturbance between both techniques. Conceptually, SGWT used three basic operations, which are split, predict, and update. The selection of a mother wavelet is also considered in the experimental assessment. As a result, the SGWT decomposition yielded better performance in terms of time detection compared with DWT, but in terms of signal accuracy, the result was doubted [186]. However, some studies discovered that WT-based decomposition is inflexible where the kernel function needs to be preselected, thus, the wavelet packet transform (WPT) was proposed to overcome the problems [187]. Arbitrarily, the WPT is capable of selecting the frequency resolution, which makes it relatively adaptable. The performance of the WPT is also experimentally outperformed in terms of accuracy for fault diagnosis purposes [187].

\subsubsection{Stockwell Transform Approach}

Wavelet transform is a robust candidate in analyzing signal, but it is very sensitive to the noise signal. The extended wavelet with phasor information known as Stockwell Transform (ST) is developed for non-linear signal detection based on moving a varying and scalable localizing Gaussian window [188-191]. ST is widely used for feature extraction in terms of harmonic spectra of the frequency or time domain [192]. The benefits of ST, which is multi-resolution, enables it to generate complex S-matrices of the parameter signals measured at the sending and receiving lines [193]. In [194], Roy et al. extracted the peak amplitude of the phase angle from an absolute S-matrix value to detect the faulty phase in the system. Due to the ability to provide good resolution on both time and frequency domains simultaneously, ST is also widely used to detect high impedance faults and distinguish them from others disturbances such as bank switching, feeder energizing, and solid faults [195]. Besides, [196] adopted ST to obtain the S-contour and various curves to detect various types of faults such as line-to-ground (SLGF), double line (LLF), double-line-to-ground (LLGF), and three-phase faults with the presence of dynamis load.

However, ST has some drawbacks while computing the signal such as large computing redundancy, time consuming nature, and storage space consumption. Therefore, a modified ST named the discrete orthogonal ST (DOST) is introduced to deliver a perfectly nonredundant picture of the input signal. The DOST has a different operation in comparison with the ST such as at smaller frequencies of the input signals, DOST samples at a smaller rate and at a higher rate [197]. Besides, fast Stockwell Transform (FST) is developed to compress a two-dimensional time-frequency matrix into a one-dimensional vector [198]. The proposed method reduces the time complexity and extract the features quickly and accurately. The FST uses the double frequency sampling where the width of the current sampling Gaussian window is set to twice the width of the previous. In [198], Jiao et al. proposed FST to identify the SLG fault of small current system. Zahra et al. proposed another faster version of FST known as a fast dynamic orthogonal ST (FDOST) to identify, supervise, and detect the fault zone with a unified power flow controller (UPFC) [199]. The FDOST method is inspired by DOST where its basis vector is represented by three parameters: $v$ (centre of frequency band), $\beta$ (width at that band), and $\tau$ (time of location). The orthogonality of the basis vector is dependent on $v, \beta$, and $\tau$ [200].

\subsubsection{Empirical Mode Decomposition Approach}

Signal processing using Empirical Mode Decomposition (EMD)-based time-frequency analysis has been proposed as a robust detector [201]. Generally, the EMD method is based the simple assumption that any data consist of simple intrinsic mode oscillation. The intrinsic mode oscillation is then filtered out from the original signal and extracted into the mono-component signal, which comprises a narrow band of frequencies to define 
the instantaneous frequency (IF). Accordingly, the signal will be decomposed into the number of intrinsic mode function (IMF) by following several conditions [202-204]. The EMD proposed by Huang et al. decomposed into mono-component IMFs presented a well-behaved Hilbert Transform (HT) and helped in obtaining IF in a non-stationary signal [201,202].

Recently, EMD and its modified version has been widely used to detect and diagnose faults of lines, faults of gears, and rotors in rotating machinery. It has also been used to detect incipient faults and structural parameters changes. Dheeraj et al. proposed pseudofault injection to the envelop for fault isolation of rotating machinery [205]. The proposed method was able to quantify statistical pattern changes in vibration data resulting from the onset of damage. However, the pattern changes suffer from mode mixing, which prevents the results obtained to be accurately classified. To overcome these problems, Ensemble Empirical Mode Decomposition is proposed (EEMD) and complete Ensemble Empirical Mode Decomposition with Adaptive Noise (CEEMDAN) is proposed to preserve the original signal and eliminate noise [206]. In [207], Hua et al. proposed an improved frequency band entropy to select the sensitive IMFs that can better reflect fault characteristics [208]. Yet, EEMD urges for a large amount of computation and risks a false decomposed component if the parameters are not properly chosen. Therefore, the CEEMDAN is proposed, where adaptive white noise is added in every decomposition stage and the left component is calculated. Since the amount of white noise added is not clearly presented, the quality of features classification might be reduced or unhealthy [206].

For fault detection in a distribution system, CEEMD is proposed to extract signal reconstruction with low computation process [117]. In this proposed technique, the amount of white noise added is mentioned to avoid setting the white noise intensity, which consumes time. However, the limitation is that the threshold value needs to be properly selected to acquire a highly accurate impedance fault and medium impedance fault detection since the peak value is nearly the same. In [209], Xiaowei et al. proposed CEEMDAN to extract the characteristic of IMFs of the zero sequence current for faulted feeder detection. The Hilbert Huang Transform (HHT) is then adopted to calculate the characteristic of instantaneous phase (CIP), characteristic of instantaneous amplitude (CIA), and characteristic instantaneous zero-sequence current polarity (CCIP) to estimate the single line to ground fault (SLGF).

\section{Challenges and Recommendations of Future Trends Schemes}

Although the detection and location schemes have been comprehensively reviewed, there are still few challenges that cannot be overlooked. This section will describe the key challenges and future recommendations of transient fault detection within the Malaysia system.

\subsection{Challenges of Transient Fault Detection in Malaysian Distribution System}

This subsection explains several challenges to work on transient fault detection in the Malaysian DS. The transient fault occurrences in the DS contributed to the extensive voltage dip due to fault propagation, which usually leads to the power quality issues. The fault propagation is of much concern due to broad usage of modern components, especially in Malaysian industrial premises. The existence of propagation faults become a challenge since the components are very sensitive to this type of disturbance, which require a robust mitigation and isolation method. In [210], the authors mentioned the cause of fault propagation in DS. In most of the cases, embedded generator and induction motor operation contributed to the fault propagation that later caused short-circuit faults. A sag propagation index (SPI) and sag propagation index asymmetrical (SPIA) could be employed to analyze the fault propagation. Since the propagation fault commonly results in voltage sag, another way to predict the fault is by testing the transformer connection to check the influence towards the sag. A study was conducted by Mustapa et al. to investigate the 
fault propagation by modelling the test system similar to the Malaysian system [211]. This is very useful for future research in Malaysia to deal with fault propagation.

There is also another challenging task in detecting transient faults since most of the employed methods are applicable to the steady-state situation rather than dynamic. Usually, the steady-state method used the steady-state fault features such as phases comparison, harmonics evaluation, and voltage value comparison [212]. Meanwhile, transient faults are categorized as dynamic since the features are sometimes uncertain wherein it is not applicable for steady-state methods [213]. To solve the problems, many methods based on transient fault features such as the energy wavelet method, Principal Component Analysis (PCA), S-Transform, and Hilbert Huang could be adopted in the detection process. However, the methods should be implemented for real-time detection to obtain an accurate value. The proposed method should be capable to communicate between the utility and consumers to provide consumption data periodically [214]. Since Malaysia is a developing country, this implementation becomes more challenging due to high cost and the need for huge storage for the data recorded.

Today, power generation in Malaysia is mainly dominated by gas and coal, accounting for $78 \%$ of the country's energy mix, and in the last eight years, Renewable Energy (RE) has emerged, adding to the country's energy mix $[215,216]$. RE is without a doubt the future in energy consumption and mix. It needs the right policies, infrastructures, and funding and has therefore been a much-debated topic not only in Malaysia, but also globally. Recently, the Energy Commission announced the implementation of the fourth cycle of the large-scale solar program (LSS4) in Malaysia [217]. Due to the evolving grid system, where the implementation of this RE, such as photovoltaic (PV), is in demand, the modification and upgrading of fault detection and classification methods for such an impact on the system might be a challenging task for the engineers. This is because the conventional protection relay can identify the low impedance fault effortlessly, but is unable to identify the high impedance fault, which usually occurs in the photovoltaic (PV) integration network. In addition, the transient fault detection also needs to be upgraded to cater to the newly grid-interconnected RE in Malaysia. This is due to several internal behaviors such as partial shading, panel contamination, and degradation component. Therefore, an upgraded fault detection scheme based on several studies is proposed for future employment [218]. Figure 13 illustrates the modification of fault detection schemes based on parameters behavior from various studies that have been conducted such as data driven, process control, and knowledge based [219]. Based on the figure, the fault usually created due to the PV array, battery, grid, and connection will be detected by fault detection and identification (FDI). Once the fault occurs, voltage and current variable (I-V) characteristics will deviate, enabling the diagnosis of the characteristics based on the normal operation mode. The voltage and current across the PV array will be measured using a combination of the Incremental Conductance (IncCond) algorithm and the Particle Swarm Optimization (PSO) based controller. The PSO algorithm is chosen as the reference current to be transferred to the PI controller booster of which the role is to achieve targeted fault-tolerance. There are two main steps involved for detecting the fault whereby in the first stage, the parameters' fault behaviors are extracted from the detecting scheme. Meanwhile, at the second stage, a training algorithm along with the pre-set data are compared with the input value from the grid in data driven analysis. Then the process control block will be modeled, and knowledge-based rules are formed based on the state condition and decision-making process.

Since the solar PV integration is widely utilized for power supply, the usage of a battery energy storage system has become a concern in order to maintain the voltage level by charging during peak hour. Efficient energy storage is very crucial to ensure its operation though it is fully charged in supporting household loads during peak demand. The battery energy storage should be capable to compensate power quality and become a backup supply when there is a disturbance in the grid system. However, the battery energy storage has a complex configuration, where it relies on battery sensor data and 
communication. Any sensor fault and communication failure could threaten not only the battery energy storage system, but also the electric vehicles and the grid system. Therefore, fault detection in the battery storage must be monitored to ensure the reliability of the power supply in grid system.

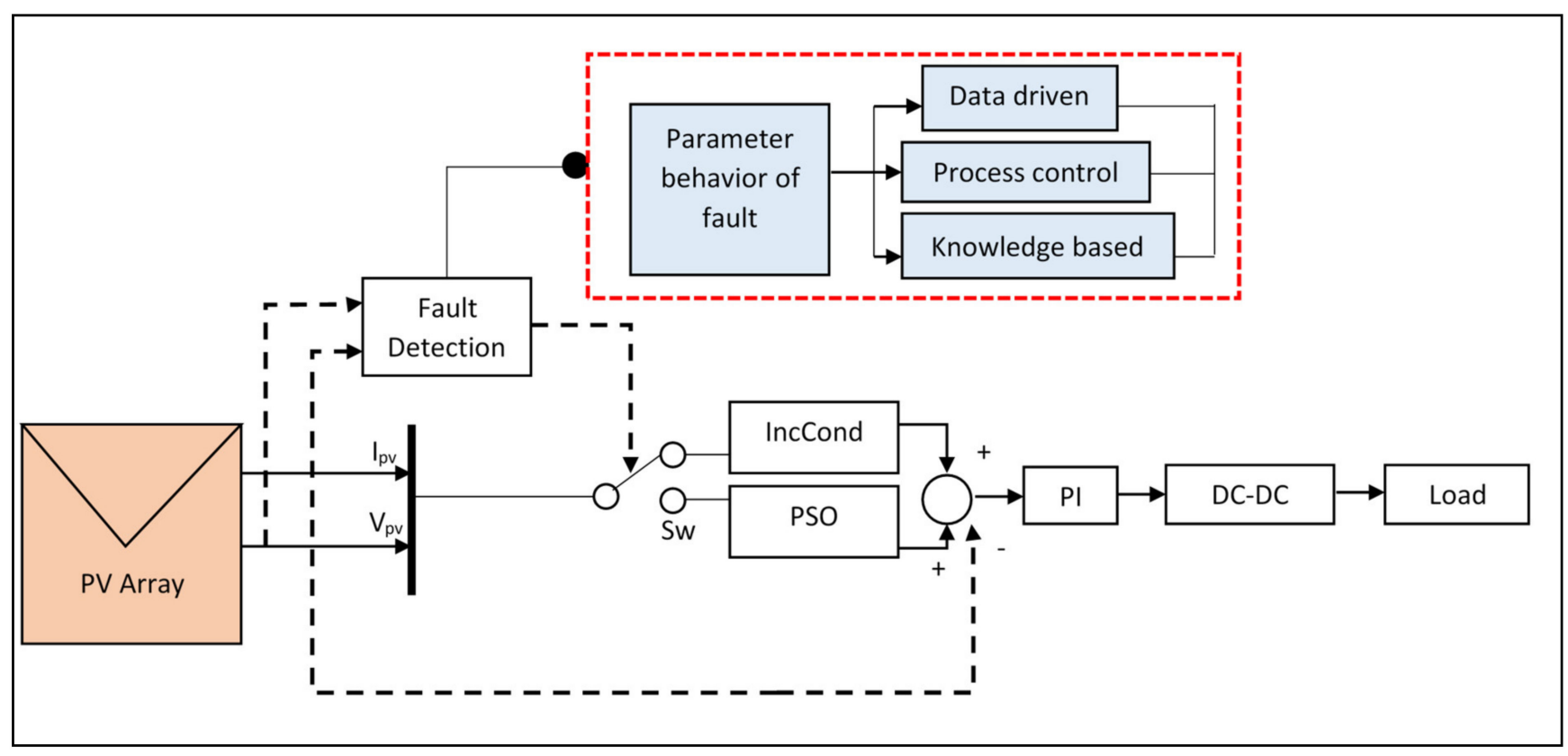

Figure 13. The architecture of proposed fault detection schemes for grid-interconnected renewable energy [218].

Other than the grid-interconnected RE, Malaysia has been uplifting the railways project as an attempt to boost the individual economist. With the evolution of the railway electrification system, the DC distribution system is widely adopted to improve the energy efficiency and reduce the weight on power system. The deployment of the DC distribution system comprises multiple power electronics converters, which will affect the system when faults occur. The converter operation mode is employed to transition from voltage control to current limiting control to eliminate overcurrent in electronic devices. Fault current limiting (FCL) will be activated when overcurrent is detected in converters such as buck converter, full-bridge multilevel converter (MMC), and thyristor-rectifier. Recently, short-circuit protection in the DC distribution system such as current derivative protection, transient energy protection, overcurrent protection, and impedance protection suffered from several limitations where it requires signal synchronization to prevent the time delay and lower accuracy. In order to overcome the drawbacks, a hybrid approach for transient fault detection is proposed. In [220], a hybrid converter-based DC distribution system was proposed to detect and locate fault, where the fault current is immediately limited by each power converter once an overcurrent is detected. In addition, the method also completely removed the noise and sensor errors. Besides that, the overhead catenary system for a high-speed railway station is easily exposed to lightning strikes, which might lead to a transient fault [221]. In [222], a finite difference time domain method (FDTD) was proposed to investigate the reflected wave in the traveling wave produced when there is a lightning strike. The lightning strike would produce travelling wave voltage through the ground wire, and it would be reflected back when reaching the contact point at the transmission pole as shown in Figure 14. In order to reduce the impact of a transient fault, FDTD is used to analyze the value of lightning surge propagation in the system, which depends on the grounding resistance value. 


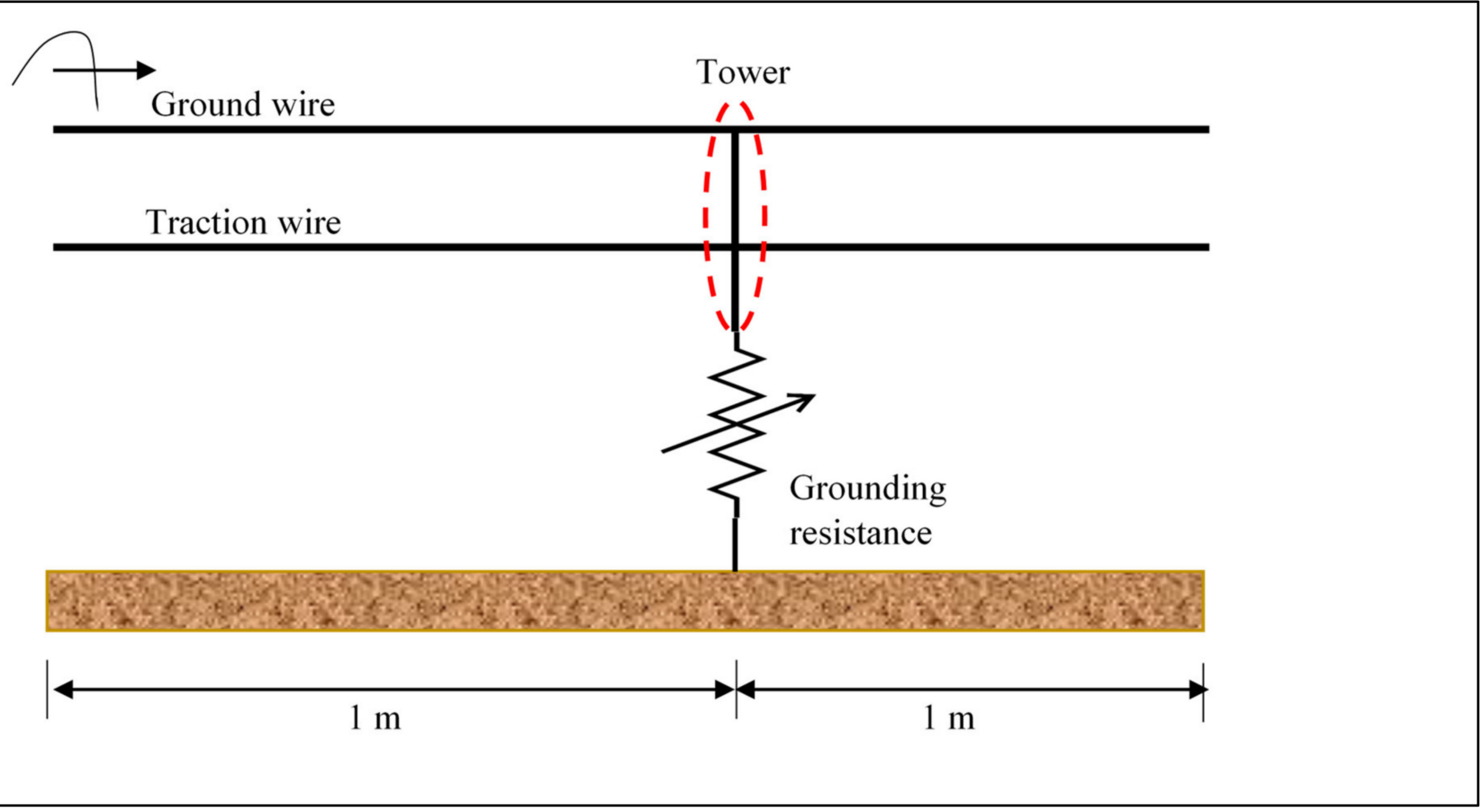

Figure 14. Catenary system high speed railway when struck with lightning [222].

\subsection{Future Recommendations}

In Sections 2-5, a review on the trends and fault detection and location issues in a distribution network for the global field and in relation to the Malaysian current system practices was conducted. Next, a comprehensive analysis was conducted to summarize all of the reviewed techniques, the key challenges, as well as the future recommendation in deploying miscellaneous electronic components within the power distribution system with reference to Section 6, Section 6.1, Section 6.2 The forthcoming technologies such as electrical vehicles and the smart grid urge several recommendations in enhancing the performance and accuracy of transient fault detection and location within the Malaysian distribution system and may be applicable to their employment in other countries.

- Several transient faults occurred in Malaysia recorded in the backwoods territory, which is difficult to be patrolled by the crews when there is a fault. Therefore, autorecloser installation in the backwoods should be increased to reduce the interruption times, thus potentially reducing the SAIDI performance.

- Due to the increased number of new technologies implemented in the Malaysian grid system, the existing standards and guideline should be regularly revised to achieve permissible leniency of the equipment to prevent damages and any unplanned system faults. For example, the evolving technology of battery energy storage needs an extensive revision on the current electrical standard since the deployment is still new in prevailing any upcoming damages.

- With the rapid progress of AI, neural networks are becoming more popular, but the limitation is still serious in the training. Big data are required for the training of every situation. However, faults are not that often, so the fault data are always small data. Several methods that could overcome the limitation exist, including creating a model that yield signals similar to the actual field data. The parameters in the created model are varied to obtain various simulation results within the actual range values. Another solution is generating synthetic data where the data production is applicable to real situation. The data are artificially created by programming based on the original data set.

- The lack of fault detection and location computation time contribute to the low distribution system performance. Furthermore, the main challenge for these methods is 
that they rely on huge amounts of representative data and cannot extrapolate beyond the boundaries of the training data. Therefore, hybrid approaches that make use of knowledge-based methods such as the wavelet method along with data-driven machine learning-based methods such as ANN can address the aforementioned problem effectively. Therefore, the classification of the fault and the clearance time of the power compensation device could be faster.

- Due to the boost of RE deployment in the Malaysian grid system, an appropriate planning and scheduling power dispatch should be deliberated. This will help to reduce the risk of fault, hence escalating the RE source generation in the Malaysian distribution system.

\section{Conclusions}

This paper provides a review of the transient fault detection and location methods in the distribution network as well as the current practice of the system and challenges for future trends in Malaysia. The key points of the paper can be summarized as follows:

1. Various techniques and improvement methods have been adopted to detect and locate various types of transient faults to mitigate power outages in the system. Various mathematical algorithms and AI approaches have been proposed to acquire an accurate fault location at a very fast speed. All parameters to acquire fault detection and location are tabulated and summarized in Table 6, whilst basic principles, advantages, and disadvantages of previous works associated with each technique are investigated and summarized in Table 8. The efficiency and robustness of individual approaches are also assessed to comply with the selected bus system. The lightning strike is prescribed as the dominant cause of transient faults and might damage the system. As a result, the system will suffer from power outages and reduced quality of power delivery.

2. From the studies conducted, fault detection and location can be categorized into conventional and knowledge-based methods. The conventional methods are economical and simple measurement setups that require less computation time. Among the conventional methods, those that are impedance based have the simplest algorithm. However, it is inaccurate for large power system networks where their application is limited due to the randomness of the grounding resistance and load fluctuation. Meanwhile, the travelling wave method is a standalone in the network configuration and needs to be installed in the presence of lateral branches of the distribution network, which is very costly. On the other hand, knowledge-based methods using AI are widely used due to their high accuracy in identifying a fault location, even in a large system, simple structure, and non-linear mapping ability. Since the conventional distribution network is under transformation to a more efficient system, this transition puts forward increased stress on the complex infrastructure for further investment to ensure safe and reliable energy supply to the consumers. Therefore, efficient and intelligent mechanisms for fault detection and location must be formulated.

3. All the reviewed AI techniques have shown promising performance in terms of fault detection and location accuracy. Based on summarization of all Artificial Intelligence methods in Table 7, SVM is seen as the most robust machine learning method to be implemented in Malaysian power distribution system. This is due to the fact that SVM has no requirement for a large amount of training data, and very fast computation speed with the lowest percentage error. However, it is suggested to configure with wavelet transform (WT) to overcome the extrapolation problems since WT has the simplest structure of transient detection process.

4. Transient fault is found to be the most frequent disturbance in Malaysian electrical systems. Transient fault has become a matter of concern nowadays, along with permanent faults, but has gained the least attention from researchers based on previous works [4,223-226]. Further, SLGF is disclosed as the most the popular approach for 
the evaluation of fault types in this paper due to common occurrences as shown in Table 6.

5. Several key challenges and recommendations for future transient fault detection and location in Malaysia have been addressed. Due to super-fast technology evolution, the bulk of electronic devices will be installed and shall not be overlooked when developing new fault detection and location methods. In order to implement a reliable distribution automation (DA) system, the enrolment of a digital fault recorder (DFR) with a robust AI technique adopted in distribution substations shall be introduced where better measurement and communication infrastructures are deployed. The methods shall be accurate and reliable enough to meet the future distribution systems' requirements in terms of continuity of supply. In this regard, the required investments, reliability, and techno-economic benefits of different schemes require broad investigations and further exploration. Technically, the key success criteria is to suit the selected technology in the Malaysian system that depend on different factors such as the topology of the distribution system under study, the availability of data and measurements, and the desired functionalities and objectives.

Table 6. Summary of methods to identify the source of faults.

\begin{tabular}{|c|c|c|c|c|c|c|c|}
\hline Author(s) & Ref. & Years & $\begin{array}{l}\text { Verified by } \\
\text { Experiment }\end{array}$ & Fault Types & Technique & Input Data & Error $(\%)$ \\
\hline Rafinia et al. & [129] & 2014 & yes & $\begin{array}{l}\text { SLGF, LLGF, } \\
\text { LLLGF }\end{array}$ & DWT-ANN & Voltage and current & $<1.50$ \\
\hline $\begin{array}{l}\text { Adeyemi } \\
\text { et al. }\end{array}$ & [130] & 2016 & yes & $\begin{array}{l}\text { SLGF, LLGF, } \\
\text { LLLGF }\end{array}$ & DWT-ANN & Current & $<1.12$ \\
\hline Yang et al. & [131] & 2017 & $\mathrm{NO}$ & $\begin{array}{c}\text { SLGF, LLGF, } \\
\text { LLLGF }\end{array}$ & ANN & Current & $<1.16$ \\
\hline $\begin{array}{l}\text { Mahmoud } \\
\text { et al. }\end{array}$ & [150] & 2018 & Yes & $\begin{array}{l}\text { PV string, } \\
\text { modules and } \\
\text { MPPT fault }\end{array}$ & ANN & Voltage and current & $<1.14$ \\
\hline Hassan et al. & [132] & 2020 & Yes & $\begin{array}{c}\text { Grid } \\
\text { connected } \\
\text { photovoltaic } \\
\text { fault }\end{array}$ & ANN & Current & $\mathrm{N} / \mathrm{A}$ \\
\hline $\begin{array}{l}\text { Muhammad } \\
\text { et al. }\end{array}$ & [151] & 2013 & Yes & $\begin{array}{l}\text { SLGF, LLGF, } \\
\text { LLLGF }\end{array}$ & FCE-Nets & Current and voltage & $\mathrm{N} / \mathrm{A}$ \\
\hline Palfi et al. & [148] & 2016 & No & $\begin{array}{c}\text { Not } \\
\text { mentioned }\end{array}$ & Fuzzy logic & $\begin{array}{l}\text { (1) Ratio of consumer } \\
\text { density to line length (D), } \\
\text { (2) Ratio of number of } \\
\text { smart consumer devices to } \\
\text { total number of } \\
\text { consumers (SM/CT). }\end{array}$ & $\mathrm{N} / \mathrm{A}$ \\
\hline Yadav et al. & [149] & 2014 & Yes & $\begin{array}{l}\text { LG, LL, LLG, } \\
\text { LLL, LLLG }\end{array}$ & $\begin{array}{c}\text { DT-Fuzzy } \\
\text { logic }\end{array}$ & Voltage and current & $<2.00$ \\
\hline Deng et al. & [154] & 2013 & Yes & SLGF. & DWT-SVM & Voltage and current & $<1.00$ \\
\hline Apisit et al. & [128] & 2012 & Yes & $\begin{array}{l}\text { SLGF, LLGF, } \\
\text { LLLGF }\end{array}$ & DWT-SVM & Current & $\mathrm{N} / \mathrm{A} *$ \\
\hline $\begin{array}{l}\text { Radhakrishnan } \\
\text { et al. }\end{array}$ & [132] & 2021 & Yes & SLGF & $\begin{array}{l}\text { Ensemble } \\
\text { DWT }\end{array}$ & Voltage & $<12.0$ \\
\hline Ray et al. & [155] & 2016 & Yes & $\begin{array}{l}\text { LG, LL, LLG, } \\
\text { LLL }\end{array}$ & WPT-SVM & Voltage and current & $<0.21$ \\
\hline Gu et al. & [161] & 2015 & No & SLGF & LS-SVM & Current & $<1.10$ \\
\hline
\end{tabular}


Table 6. Cont.

\begin{tabular}{|c|c|c|c|c|c|c|c|}
\hline Author(s) & Ref. & Years & $\begin{array}{l}\text { Verified by } \\
\text { Experiment }\end{array}$ & Fault Types & Technique & Input Data & Error $(\%)$ \\
\hline Liang et al. & [227] & 2018 & Yes & SLGF & GA & Voltage and current & $<0.22$ \\
\hline Masoud et al. & [228] & 2012 & No & $\begin{array}{l}\text { SLGF, LLGF, } \\
\text { LLLGF }\end{array}$ & GA & Voltage and current & $<1.00$ \\
\hline Jamali et al. & [229] & 2015 & No & SLGF & GA & Voltage & $<2.00$ \\
\hline Sanad et al. & [230] & 2017 & Yes & LG, LLLG & $\begin{array}{l}\text { WOA and } \\
\text { GA }\end{array}$ & $\mathrm{N} / \mathrm{A}$ & $<1.00$ \\
\hline Rai et al. & [137] & 2021 & Yes & $\begin{array}{l}\text { LG, LL, LLG, } \\
\text { LLL }\end{array}$ & $\mathrm{CNN}$ & Voltage and current & $<0.5$ \\
\hline Lei et al. & [138] & 2019 & Yes & $\begin{array}{l}\text { Insulator and } \\
\text { nest fault }\end{array}$ & $\begin{array}{c}\text { Faster } \\
\text { R-CNN }\end{array}$ & Image & $<2.5$ \\
\hline
\end{tabular}

* N/A: Information not available in the reference paper.

Table 7. Summary of advantages and disadvantages of methods.

\begin{tabular}{|c|c|c|c|c|c|}
\hline Method & Cost & $\begin{array}{l}\text { Computational } \\
\text { Process }\end{array}$ & $\begin{array}{c}\text { Amount of Data } \\
\text { Acquired }\end{array}$ & $\begin{array}{l}\text { Sampling } \\
\text { Frequency }\end{array}$ & Accuracy \\
\hline TW & High & Fast & Small & Low High & Accurate \\
\hline Impedance Base & Low & Slow & Small & Low & Less accurate \\
\hline ANN & High & Fast & Big & Low and high & $\begin{array}{l}\text { Depends on } \\
\text { amount of data }\end{array}$ \\
\hline $\mathrm{CNN}$ & High & $\begin{array}{l}\text { Fast (sinusoidal signal) } \\
\text { and slow (image) }\end{array}$ & Big & High & Accurate \\
\hline LSTM & High & $\begin{array}{c}\text { Dependent (slow } \\
\text { when number of layer } \\
\text { increase) }\end{array}$ & Big & Low and high & Accurate \\
\hline FL & High & Fast & Small & Low and high & $\begin{array}{l}\text { Depends on } \\
\text { amount of data }\end{array}$ \\
\hline SVM & High & Fast & Small & Low and high & Accurate \\
\hline GA & High & Fast & Big & Low and high & $\begin{array}{l}\text { Depends on } \\
\text { amount of data }\end{array}$ \\
\hline
\end{tabular}

Table 8. Advantages and disadvantages of fault detection methods.

\begin{tabular}{|c|c|c|c|c|}
\hline Method & Advantages & Disadvantages & Application in DS & $\begin{array}{l}\text { Computational } \\
\text { Time Process }\end{array}$ \\
\hline $\begin{array}{l}\text { Travelling Wave } \\
{[5-7,45,108]}\end{array}$ & $\begin{array}{l}\text { - Not affected by the } \\
\text { operation mode. } \\
\text { Not dependent on the } \\
\text { network configuration } \\
\text { and devices installed. }\end{array}$ & $\begin{array}{l}\text { - Very sensitive to sampling } \\
\text { frequency since the accuracy } \\
\text { algorithm depends on it. } \\
\text { Requires high sampling rate } \\
\text { and high-speed } \\
\text { communication. }\end{array}$ & $\begin{array}{l}\text { Protection, fault } \\
\text { distance accuracy, } \\
\text { transient detection }\end{array}$ & Fast. \\
\hline $\begin{array}{l}\text { Impedance Base } \\
{[45,118-122]}\end{array}$ & $\begin{array}{l}\text { - Low implementation } \\
\text { cost. }\end{array}$ & $\begin{array}{l}\text { - } \quad \text { No convergence or false root. } \\
\text { Limited to fault path } \\
\text { resistance, line loading and } \\
\text { sources parameters. } \\
\text { - } \quad \begin{array}{l}\text { Easily influenced by load and } \\
\text { power parameters. }\end{array}\end{array}$ & $\begin{array}{l}\text { Protection, fault } \\
\text { distance accuracy, } \\
\text { low sampling rate } \\
\text { detection }\end{array}$ & $\begin{array}{l}\text { Slow due to the } \\
\text { manually } \\
\text { calculated }\end{array}$ \\
\hline
\end{tabular}


Table 8. Cont.

\begin{tabular}{|c|c|c|c|c|}
\hline Method & Advantages & Disadvantages & Application in DS & $\begin{array}{l}\text { Computational } \\
\text { Time Process }\end{array}$ \\
\hline $\begin{array}{l}\text { ANN }[45,129- \\
\quad 134,231]\end{array}$ & $\begin{array}{l}\text { - } \quad \text { Simple architecture, fast } \\
\text { and easy to run. } \\
\text { - } \quad \text { Easier to attain the target. }\end{array}$ & $\begin{array}{l}\text { Difficult to find the } \\
\text { appropriate features to } \\
\text { comprehend the } \\
\text { interrelationship between the } \\
\text { input and the desired output. } \\
\text { Requires high amount of data } \\
\text { for training and testing. } \\
\text { Trial and error case used to } \\
\text { identify some. }\end{array}$ & $\begin{array}{l}\text { Cyberspace } \\
\text { security, fault and } \\
\text { failure analysis, } \\
\text { classification, and } \\
\text { prediction. }\end{array}$ & Very fast \\
\hline $\begin{array}{c}\text { CNN } \\
{[135-138,140]}\end{array}$ & $\begin{array}{l}\text { Provide high accuracy } \\
\text { testing data at fewer } \\
\text { training data. } \\
\text { very computationally } \\
\text { effective during online } \\
\text { mode }\end{array}$ & $\begin{array}{l}\text { - Computationally expensive } \\
\text { when trained in offline mode. } \\
\text { Incapable to detect complex } \\
\text { features since it only learns to } \\
\text { detect simple features. } \\
\text { - Not sensitive to time features } \\
\text { of time series }\end{array}$ & $\begin{array}{l}\text { Fault detection and } \\
\text { location of } \\
\text { distribution power } \\
\text { system with DGs } \\
\text { implementation }\end{array}$ & $\begin{array}{l}\text { Very fast for } \\
\text { signal but slow } \\
\text { for image }\end{array}$ \\
\hline LSTM [139-141] & $\begin{array}{l}\text { Better fusion time } \\
\text { characteristics of different } \\
\text { part status }\end{array}$ & $\begin{array}{l}\text { Training time increase with } \\
\text { the number of layers } \\
\text { increases }\end{array}$ & $\begin{array}{l}\text { Fault detection of } \\
\text { distribution power } \\
\text { system with DGs } \\
\text { and multi-machine } \\
\text { implementation }\end{array}$ & $\begin{array}{l}\text { Depending on } \\
\text { the hidden layer. } \\
\text { The higher the } \\
\text { number of layer, } \\
\text { the slower the } \\
\text { simulation time. }\end{array}$ \\
\hline $\begin{array}{c}\text { FL } \\
{[143-148,232]}\end{array}$ & $\begin{array}{l}\text { - } \\
\text { ubility to cope with } \\
\text { - } \quad \text { Quick response. } \\
\text { - } \quad \text { Appropriate for online } \\
\text { platform. } \\
\text { - Does not require training. }\end{array}$ & $\begin{array}{l}\text { Difficult to determine global } \\
\text { minimum of fuzzy } \\
\text { membership function. } \\
\text { Slow features definition and } \\
\text { extraction. }\end{array}$ & $\begin{array}{l}\text { Fault position } \\
\text { accuracy, power } \\
\text { islanding detection, } \\
\text { fault discrimination }\end{array}$ & Slow \\
\hline $\begin{array}{l}\text { SVM } \\
{[45,128,154-} \\
158,231]\end{array}$ & $\begin{array}{l}\text { - } \quad \text { Fast learning speed. } \\
\text { - } \quad \text { Upall sample demand. } \\
\text { generalization error } \\
\text { independent of space } \\
\text { dimension. }\end{array}$ & $\begin{array}{l}\text { - Need to choose kernel } \\
\text { function to acquire the best } \\
\text { performance. }\end{array}$ & $\begin{array}{l}\text { Forecasting, fault } \\
\text { and failure analysis. }\end{array}$ & Very fast \\
\hline $\begin{array}{c}\text { GA } \\
{[148,162-165]}\end{array}$ & $\begin{array}{l}\text { - Can regulate the } \\
\text { computation speed. } \\
\text { The dimension of } \\
\text { possible solution is low. }\end{array}$ & $\begin{array}{l}\text { - The accuracy of FL is } \\
\text { questionable due to random } \\
\text { process. }\end{array}$ & $\begin{array}{l}\text { Forecasting, fault } \\
\text { classification }\end{array}$ & $\begin{array}{l}\text { Not consistent } \\
\text { due to most } \\
\text { process are } \\
\text { random }\end{array}$ \\
\hline
\end{tabular}

Author Contributions: Conceptualization, M.Z.A.A.K. and S.H.A.; methodology, S.H.A.; software, S.H.A.; validation, M.Z.A.A.K., N.F.A.A. and U.A.U.A.; formal analysis, M.Z.A.A.K. and S.H.A.; investigation, M.Z.A.A.K.; resources, S.H.A.; data curation, M.Z.A.A.K., and N.F.A.A.; writingoriginal draft preparation, S.H.A.; writing-review and editing, M.Z.A.A.K., N.F.A.A., and U.A.U.A.; visualization, M.Z.A.A.K., N.F.A.A., and U.A.U.A.; supervision, M.Z.A.A.K., N.F.A.A., and U.A.U.A.; project administration, M.Z.A.A.K.; funding acquisition, N.F.A.A. All authors have read and agreed to the published version of the manuscript.

Funding: The authors would like to thank FRGS (20180112FRGS) and Universiti Tenaga Nasional for the BOLD Scholarship. Special thanks to Tenaga Nasional Berhad (Grid Maintenance) team for their kind support on the data.

Institutional Review Board Statement: Not applicable. 
Conflicts of Interest: The authors declare no conflict of interest.

\section{References}

1. Barros, J.D.; Ferreira, E.F.; Barros, J.D. Faults Monitoring System in the Electric Power Grid of Medium Voltage. Procedia Comput. Sci. 2018, 130, 696-703.

2. Trindade, F.C.L.; Freitas, W. Low Voltage Zones to Support Fault Location in Distribution Systems with Smart Meters. IEEE Trans. Smart Grid 2017, 8, 2765-2774. [CrossRef]

3. Barakat, M.A.; Hatata, A.Y.; Badran, E.A. Protection of transformer due to external fault between two voltage levels using overvoltage protection and sequence component of currents. Electr. Power Syst. Res. 2020, 184, 106339. [CrossRef]

4. Zin, A.A.M.; Abdul Karim, S.P. Protection system analysis using fault signatures in Malaysia. Int. J. Electr. Power Energy Syst. 2013, 45, 194-205. [CrossRef]

5. Costa, F.B.; Lopes, F.V.; Silva, K.M.; Dantas, K.M.C.; França, R.L.S.; Leal, M.M.; Ribeiro, R.L.A. Mathematical development of the sampling frequency effects for improving the two-terminal traveling wave-based fault location. Int. J. Electr. Power Energy Syst. 2020, 115, 105502. [CrossRef]

6. Rui, L.; Chenglei, L.; Nan, P.; Menghan, C.; Fei, W. Fault location for power grid based on transient travelling wave data fusion via asynchronous voltage measurements. Int. J. Electr. Power Energy Syst. 2017, 93, 426-439. [CrossRef]

7. Wang, D.; Hou, M. Travelling wave fault location algorithm for LCC-MMC-MTDC hybrid transmission system based on Hilbert-Huang transform. Electr. Power Energy Syst. 2020, 121, 106125. [CrossRef]

8. TNB. Integrated Annual Report 2017; Baha Malaysia: Kuala Lumpur, Malaysia, 2017.

9. Nalley, S.; Angelina La Rose, A.A. Annual Energy Outlook 2018 with Projections to 2050. Available online: https: / / www.globalenergyinstitute.org/eias-annual-energy-outlook-2018-ups-downs\#: \{\}:text=Domestic $\% 20$ Supply $\% 20 \% 26 \% 20$ Demand\%3A\%20U.S.\%20energy,of\%20about\%200.4\%25\%20per\%20year (accessed on 20 April 2020).

10. Esmail, M.; Sadegh, M.; Hosseinnezhad, V. Reliability modeling of process-oriented smart monitoring in the distribution systems. Electr. Power Energy Syst. 2019, 109, 20-28.

11. Bahmanyar, A.; Jamali, S.; Estebsari, A.; Bompard, E. A comparison framework for distribution system outage and fault location methods. Electr. Power Syst. Res. 2017, 145, 19-34. [CrossRef]

12. Weng, G.; Huang, F.; Tang, Y.; Yan, J.; Nan, Y.; He, H. Fault-tolerant location of transient voltage disturbance source for DG integrated smart grid. Electr. Power Syst. Res. 2017, 144, 13-22. [CrossRef]

13. Bíscaro, A.A.P.; Pereira, R.A.F.; Kezunovic, M.; Mantovani, J.R.S. Integrated Fault Location and Power-Quality Analysis in Electric Power Distribution Systems. IEEE Trans. Power Deliv. 2016, 31, 428-436. [CrossRef]

14. Amir, S.; Askarian, H.; Hossein, S.; Sadeghi, H.; Razavi, F.; Nasiri, A. An overview of microgrid protection methods and the factors involved. Renew. Sustain. Energy Rev. 2016, 64, 174-186.

15. Saha, M.M.; Izykowski, J.J.; Rosolowski, E. Fault Location on Power Networks; Springer Science \& Business Media: Berlin/Heidelberg, Germany, 2009; ISBN 1848828861.

16. Zhu, J.; Zhou, N. Analysis of the fault type for adaptive single-phase autoreclosure. IEEE Power Energy Soc. Gen. Meet. 2015, 1, $1-5$.

17. Charbonneau, P.-L. Network Fault Monitoring vs. Network Performance Monitoring. Available online: https://obkio.com/blog/ fault-monitoring-vs-performance-monitoring/ (accessed on 20 May 2021).

18. Distribution Code For Peninsular Malaysia, Sabah \& F.T. Labuan (Amendments) 2017. Available online: https://www.st.gov.my/ en/contents / publications / guidelines_electricity/2017/Distribution\%20Code\%20For\%20Peninsular\%20Malaysia\%20Sabah\% 20\%20F.T.\%20Labuan\%20Amendments\%202017_V5.pdf (accessed on 15 May 2021).

19. McGranaghan, M.; Beaulieu, G. Update on IEC 61000-3-6: Harmonic Emission Limits for Customers Connected to MV, HV, and EHV. In Transmission and Distribution Conference and Exhibition; IEEE: Piscataway, NJ, USA, 2006; pp. 1158-1161.

20. Society, E. IEEE Guide—Adoption of IEC/TR 61000-3-7: 2008, ELECTROMAGNETIC Compatibility ( EMC )—Limits—Assessment of Emission Limits for the Connection of Fluctuating Installations to MV, HV and EHV Power Systems; IEEE: Piscataway, NJ, USA, 2008; ISBN 9780738172859.

21. Society, E. IEEE Recommended Practice for Monitoring Electric Power Quality; IEEE: Piscataway, NJ, USA, 2009; Volume 2009, ISBN 9780738159393.

22. IEEE. IEEE Guide for Determining Fault Location on AC Transmission and Distribution Lines. In Proceedings of the IEEE Std C37.114-2014 (Revision of IEEE Std C37.114-2004); IEEE: Piscataway, NJ, USA, 2015; pp. 1-76.

23. IEEE. IEEE Guide for the Application of Transient Recovery Voltage for AC High-Voltage Circuit Breakers with Rated Maximum Voltage above $1000 \mathrm{~V}$; IEEE Std C37011 ${ }^{\mathrm{TM}-}$; IEEE: Piscataway, NJ, USA, 2019; Volume 2019, pp. 1-213.

24. Society, I. IEEE Recommended Practice for Electric Power Distribution System Analysis; IEEE Std 1729-2014; IEEE: Piscataway, NJ, USA, 2014.

25. IEEE. Recommended Practice for Industrial and Commercial Power Systems Analysis; IEEE: Piscataway, NJ, USA, 1998 ; ISBN 1559379685.

26. Khan, R.; McLaughlin, K.; Laverty, D.; Sezer, S. Design and Implementation of Security Gateway for Synchrophasor Based Real-Time Control and Monitoring in Smart Grid. IEEE Access 2017, 5, 11626-11644. [CrossRef]

27. Ahmed, S.; Lee, Y.; Hyun, S.H.; Koo, I. Feature Selection-Based Detection of Covert Cyber Deception Assaults in Smart Grid Communications Networks Using Machine Learning. IEEE Access 2018, 6, 27518-27529. [CrossRef] 
28. IEEE Standard for Low-Rate Wireless Networks; IEEE Std 802.15.4-2015 (Revision of IEEE Std 802.15.4-2011); IEEE: Piscataway, NJ, USA, 2016; pp. 1-709.

29. Cleveland, F.M. IEC 62351-7: Communications and Information Management Technologies-Network and System Management in Power System Operations. In Proceedings of the 2008 IEEE/PES Transmission and Distribution Conference and Exposition, Chicago, IL, USA, 21-24 April 2008; pp. 1-4.

30. Sánchez, G.; Gómez, I.; Luque, J.; Benjumea, J.; Rivera, O. Using Internet protocols to implement IEC 60870-5 telecontrol functions. IEEE Trans. Power Deliv. 2010, 25, 407-416. [CrossRef]

31. IEEE/IEC. Measuring Relays and Protection Equipment_Part 24: Common Format for Transient Data Exchange (COMTRADE) for Power Systems; IEEE/IEC: Piscataway, NJ, USA, 2013; ISBN 2831886376.

32. American National Standards Institute (ANSI). American National Standard For Utility Industry End Device Data Tables ANSI C12.19-2008; American National Standard Institute: New York, NY, USA, 2014.

33. Huanzhen, H.; Yong, Z.; Zhenxing, L.; Min, Z. Fault Detection of Modular Multilevel Converter with Kalman Filter Method. In Proceedings of the 2019 CAA Symposium on Fault Detection, Supervision and Safety for Technical Processes (SAFEPROCESS), Xiamen, China, 5-7 July 2019; pp. 251-256.

34. The Malaysian Grid Code. Available online: https://www.st.gov.my/ms/contents/presentations/malaysian_grid_and_ distribution_code_2010/introduction\%20to\%20grid\%20code.pdf (accessed on 15 May 2021).

35. Tenaga Nasional Berhad. Reimagining Utility of the Future. In Proceedings of the Conference of the Electric Power Supply Industry (CEPSI 2018), Kuala Lumpur, Malaysia, 17-22 September 2018; pp. 1-344.

36. Group, C.A. IEEE Guide for Online Monitoring and Recording Systems for Transient Overvoltages in Electric Power Systems IEEE SA Board of Governors; IEEE: Piscataway, NJ, USA, 2015; ISBN 9780738199115.

37. American National Standards Institute. IEEE Recommended Practice for Calculating Short-Circuit Currents in Industrial and Commercial Power Systems; IEEE: Piscataway, NJ, USA, 2006; pp. 1-314.

38. Oh, J.H.; Kim, J.C. Feature extraction of fault currents associated with multi-shot reclosing scheme in power distribution system. Int. J. Electr. Power Energy Syst. 2002, 24, 79-85. [CrossRef]

39. Milosevic, D.; Djurisic, Z. A new technique for improving stability of distributed synchronous generators during temporary faults in a distribution network. Int. J. Electr. Power Energy Syst. 2018, 100, 299-308. [CrossRef]

40. Filomena, A.D.; Resener, M.; Salim, R.H.; Bretas, A.S. Distribution systems fault analysis considering fault resistance estimation. Int. J. Electr. Power Energy Syst. 2011, 33, 1326-1335. [CrossRef]

41. Surisunthon, S.; Tayjasanant, T. Impacts of Distributed Generation's Locations, Sizes, Operation Modes and Transformer Connections on Voltage Sag Assessment. In Proceedings of the TENCON 2011-2011 IEEE Region 10 Conference, Bali, Indonesia, 21-24 November 2011.

42. Lubkeman, D.L.; Member, S.; Girgis, A.A. Automated fault location and diagnosis on electric power distribution feeders. IEEE Trans. Power Deliv. 1997, 12, 801-809.

43. Shi, Y.; Baran, M.E. An Automated Model Based Fault Locating Method for Distribution Systems. In Proceedings of the 2016 IEEE/PES Transmission and Distribution Conference and Exposition, Dallas, TX, USA, 3-5 May 2016.

44. Chow, M.-Y.; Thrower, J.P.; Taylor, L.S. Neural-Fuzzy Hybrid System for Distribution Fault Causes Identification MO-yuen. In Proceedings of the 1993 Second International Forum on Applications of Neural Networks to Power Systems, Yokohama, Japan, 19-22 April 1993; pp. 427-431.

45. Gururajapathy, S.S.; Mokhlis, H.; Illias, H.A. Fault location and detection techniques in power distribution systems with distributed generation: A review. Renew. Sustain. Energy Rev. 2017, 74, 949-958. [CrossRef]

46. Moosavi, S.S.; Kazemi, A.; Akbari, H. A comparison of various open-circuit fault detection methods in the IGBT-based DC/AC inverter used in electric vehicle. Eng. Fail. Anal. 2019, 96, 223-235. [CrossRef]

47. Youssef, A.B.; Khojet, S.; Khil, E.; Belkhodja, I.S. Open-circuit fault diagnosis and voltage sensor fault tolerant control of a single phase pulsed width modulated rectifier. Math. Comput. Simul. 2017, 131, 234-252. [CrossRef]

48. Nandi, R.; Panigrahi, B.K. Detection of Fault in a Hybrid Power System Using Wavelet Transform. In Proceedings of the Michael Faraday IET International Summit 2015, Kolkata, India, 12-13 September 2015; pp. 203-206.

49. Sankaran, C. Power Quality; CRC Press: Boca Raton, FL, USA, 2002; ISBN 0849310407.

50. Energy Commission of Malaysia. Industri Pembekalan Elektrik di Malaysia; Energy Commission of Malaysia: Putrajaya, Malaysia, 2008; p. 164.

51. Energy Commission of Malaysia. Electricity Supply Industry in Malaysia; Energy Commission of Malaysia: Putrajaya, Malaysia, 2009; p. 90.

52. Electricity Supply Industry: Performance and Statistical Information. 2010. Available online: https://meih.st.gov.my/documents / 10620/e92bbc28-ff35-4e80-8981-a849b2fce14b (accessed on 15 May 2021).

53. Suruhanjaya Tenaga. Electricity Supply Industry Malaysia 2011; Malaysia Energy Information Hub: Putrajaya, Malaysia, 2011.

54. Suruhanjaya Tenaga. Malaysia Electricity Supply Industry in Malaysia_Performance and Statistical Information; Malaysia Energy Information Hub: Putrajaya, Malaysia, 2008; p. 86.

55. Suruhanjaya Tenaga. Malaysia Industri Pembekalan Elektrik di Malaysia: Maklumat Prestasi dan Statistik; Suruhanjaya Tenaga Energy Commission: Putrajaya, Malaysia, 2010; p. 103. 
56. Energy Commission. Performance and Statistical Information on Electricity Supply Industry in Malaysia; Suruhanjaya Tenaga Energy Commission: Sabah, Malaysia, 2014; p. 111.

57. Energy Commission of Malaysia. Performance and Statistical Information on Electricity Supply Industry in Malaysia; Suruhanjaya Tenaga Energy Commission: Sabah, Malaysia, 2015; p. 97.

58. Energy Commission of Malaysia. Performance and Statistical Information in Malaysia 2016; Suruhanjaya Tenaga Energy Commission: Sabah, Malaysia, 2016; p. 103.

59. Energy Commission of Malaysia. Performance and Statistical Information on Electricity Supply Industry in Malaysia 2017; Suruhanjaya Tenaga Energy Commission: Sabah, Malaysia, 2017; pp. 1-150.

60. Energy Commission of Malaysia. Performance and Statistical Information on Electricity Supply Industry in Malaysia 2018; Energy Commission: Kuala Lumpur, Malaysia, 2018; pp. 1-132.

61. Farughian, A.; Kumpulainen, L.; Kauhaniemi, K. Review of methodologies for earth fault indication and location in compensated and unearthed MV distribution networks. Electr. Power Syst. Res. 2018, 154, 373-380. [CrossRef]

62. Jamali, S.; Bahmanyar, A.; Bompard, E. Fault location method for distribution networks using smart meters. Measurement 2017, 102, 150-157. [CrossRef]

63. Hasan, M. Study of Switching Transient Over Voltage Due to Transient Short Circuit Fault in a Power Distribution Network. In Proceedings of the 2019 International Conference on Robotics, Electrical and Signal Processing Techniques (ICREST), Dhaka, Bangladesh, 10-12 January 2019; pp. 146-151.

64. Bollen, M.H.J.; Styvaktakis, E.; Gu, I.Y.H. Categorization and analysis of power system transients. IEEE Trans. Power Deliv. 2005, 20, 2298-2306. [CrossRef]

65. Ghanbari, T.; Farjah, E.; Naseri, F.; Tashakor, N.; Givi, H.; Khayam, R. Solid-state capacitor switching transient limiter based on kalman filter algorithm for mitigation of capacitor bank switching transients. Renew. Sustain. Energy Rev. 2018, 90, $1069-1081$. [CrossRef]

66. Saad, H.; Rault, P.; Dennetière, S. Study on transient overvoltages in converter station of MMC-HVDC links. Electr. Power Syst. Res. 2018, 160, 397-403. [CrossRef]

67. Shariatinasab, R.; Kermani, B.; Gholinezhad, J. Transient modeling of the wind farms in order to analysis the lightning related overvoltages. Renew. Energy 2019, 132, 1151-1166. [CrossRef]

68. Smith, J.C.; Hensley, G.; Ray, L. IEEE recommended practice for monitoring electric power quality. IEEE Std. 2009. [CrossRef]

69. Mehranzamir, K.; Davarpanah, M.; Abdul-Malek, Z.; Afrouzi, H.N. Discriminating cloud to ground lightning flashes based on wavelet analysis of electric field signals. J. Atmos. Solar Terrestrial Phys. 2018, 181, 127-140. [CrossRef]

70. Ahmad, N.I.; Ab-Kadir, M.Z.A.; Izadi, M.; Azis, N.; Radzi, M.A.M.; Zaini, N.H.; Nasir, M.S.M. Lightning protection on photovoltaic systems: A review on current and recommended practices. Renew. Sustain. Energy Rev. 2018, 82, 1611-1619. [CrossRef]

71. Sidik, M.A.B.; Shahroom, H.B.; Salam, Z.; Buntat, Z.; Nawawi, Z.; Ahmad, H.; Jambak, M.I.; Arief, Y.Z. Lightning monitoring system for sustainable energy supply: A review. Renew. Sustain. Energy Rev. 2015, 48, 710-725. [CrossRef]

72. Lim, S.Y.; Kim, K.H.; Rhee, S.B.; Kim, S.B.; Lee, K.Y. Transient state analysis of lightning surge on distribution systems. IFAC-PapersOnLine 2015, 48, 132-136. [CrossRef]

73. Borghetti, A.; Nucci, C.A.; Paolone, M.; Bernardi, M. A Statistical Approach for Estimating the Correlation between Lightning and Faults in Power Distribution Systems. In Proceedings of the 2006 International Conference on Probabilistic Methods Applied to Power Systems, Stockholm, Sweden, 11-15 June 2006; pp. 1-7.

74. Rakov, V.A.; Uman, M.A. Lightning: Physics and Effects; Cambridge University Press: Cambridge, UK, 2003 ; ISBN 0521583276.

75. Almeida, A.C.; Rocha, B.R.P.; De Souza, J.R.S.; Monteiro, J.H.A.; Sa, J.A.S. Cloud-to-Ground Lightning Observations over the Eastern Amazon Region: Subsidies for the Protection of Electric Systems. In Proceedings of the 2010 30th International Conference on Lightning Protection (ICLP), Cagliari, Italy, 13-17 September 2010.

76. Betz, H.D.; Schmidt, K.; Oettinger, P.; Wirz, M. Lightning detection with 3-D discrimination of intracloud and cloud-to-ground discharges. Geophys. Res. Lett. 2004, 31, 1-4. [CrossRef]

77. Salimi, B.; Abdul-Malek, Z.; Mirazimi, S.J.; Mehranzamir, K. Investigation of short base line lightning detection system by using time of arrival method. Adv. Intell. Syst. Comput. 2013, 182, 141-147.

78. Li, C.; Xin, Z.; Jianguo, W.; Quanxin, L.; Wenbo, Y.; Yadong, F.A.N. Error Analysis of Total Lightning Location System Based on Monte Carlo Method. In Proceedings of the 2018 34th International Conference on Lightning Protection (ICLP), Rzeszow, Poland, 2-7 September 2018; pp. 1-5.

79. Naccarato, K.P.; De Paiva, A.R.; Saba, M.M.F.; Schumann, C.; Silva, J.C.O.; Ferro, M.A.S. Preliminary Comparison of Direct Electric Current Measurements in Lightning Rods and Peak Current Estimates from Lightning Location Systems. In Proceedings of the 2017 International Symposium on Lightning Protection (XIV SIPDA), Natal-RN, Brazil, 2-6 October 2017; pp. 319-323.

80. Cho, H.; Choi, N.; Lee, B. Oscillation Recognition Using a Geometric Feature Extraction Process Based on Periodic Time-Series Approximation. IEEE Access 2020, 8, 34375-34386. [CrossRef]

81. De Apráiz, M.; Barros, J.; Diego, R.I. A real-time method for time-Frequency detection of transient disturbances in voltage supply systems. Electr. Power Syst. Res. 2014, 108, 103-112. [CrossRef] 
82. Chakraborty, A.; Mandal, R. A Novel Technique Employing DWT-Based Envelope Analysis for Detection of Power System Transients. In Proceedings of the International Conference on Energy, Communication, Data Analytics and Soft Computing (ICECDS), Chennai, India, 1-2 August 2017; pp. 346-350.

83. Li, B.; He, J.; Li, Y.; Li, B.; Wen, W. High-speed directional pilot protection for MVDC distribution systems. Int. J. Electr. Power Energy Syst. 2020, 121, 106141. [CrossRef]

84. Rasoulpoor, M.; Banejad, M. A correlation based method for discrimination between inrush and short circuit currents in differential protection of power transformer using Discrete Wavelet Transform: Theory, simulation and experimental validation. Int. J. Electr. Power Energy Syst. 2013, 51, 168-177. [CrossRef]

85. Ali, E.; Helal, A.; Desouki, H.; Shebl, K.; Abdelkader, S.; Malik, O.P. Power transformer differential protection using current and voltage ratios. Electr. Power Syst. Res. 2018, 154, 140-150. [CrossRef]

86. Peres, L.M.; Silva, K.M. Power transformer protection using an instantaneous-current-value negative sequence differential element. Int. J. Electr. Power Energy Syst. 2019, 108, 96-106. [CrossRef]

87. Ukil, A.; Yeap, Y.M.; Satpathi, K. Power systems frequency estimation using amplitude tracking square wave for low-end protective relays. Meas. J. Int. Meas. Confed. 2019, 141, 70-84. [CrossRef]

88. Chano, S.R.; Miller, D.; Afonso, J.; Allen, M.; Balasiu, F.; Best, M.; Crellin, R.; Deronja, A.; Donahoe, K.; Fontana, D.; et al. Ancillary Protective and Control Functions Common to Multiple Protective Relays; IEEE: Piscataway, NJ, USA, 2011; ISBN 9781457704963.

89. Ahmed, M.M. New Supervisory Control and Data Acquisition (SCADA) Based Fault Isolation System for Low Voltage Distribution Systems. In Proceedings of the International Conference on Computer and Communication Engineering (ICCCE'10), Barcelona, Spain, 10-11 June 2021; pp. 1-6.

90. Ahmed, M.; Lian, S. Novel Automated Fault Isolation System on Low Voltage Distribution Automation System. In Proceedings of the 2013 UKSim 15th International Conference on Computer Modelling and Simulation, Cambridge, UK, 10-12 April 2013; pp. 593-599.

91. Zhang, S.; Rong, J.; Wang, B. A privacy protection scheme of smart meter for decentralized smart home environment based on consortium blockchain. Int. J. Electr. Power Energy Syst. 2020, 121, 106140. [CrossRef]

92. Rachidi, F.; Convenor; Borghetti, A.; Britten, T.; Cook, J.; Diego, A.G.; Geldenhuys, H.; Grcev, L.; Haddad, A.; Henriksen, T.; et al. Protection of Medium Voltage and Low Voltage Networks Againts Lightning Part 2: Lightning Protection of Medium Voltage Networks. CIGRE 2010, 2010, 1-39.

93. Rakov, V.A.; Borghetti, A.; Bouquegneau, C.; Chisholm, W.; Cooray, V.; Cummins, K.; Diendorfer, G.; Heidler, F.; Hussein, A.M.; Ishii, M.; et al. Lightning Parameters for Engineering Applications; International Council on Large Electric Systems (CIGRE): Paris, France, 2013.

94. International Electrotechnical Commission. IEC 60060-1: High Voltage Test Techniques-Part I: General Definitions And Test Requirements; International Electrotechnical Commission (IEC): Geneva, Switzerland, 2010.

95. Lovrić, D.; Vujević, S.; Modrić, T. On the estimation of Heidler function parameters for reproduction of various standardized and recorded lightning current waveshapes. Int. Trans. Electr. Energy Syst. 2013, 23, 290-300. [CrossRef]

96. Lovri, D. Exponential approximation of the Heidler function for the reproduction of lightning current waveshapes. Electr. Power Syst. Res. 2010, 80, 1293-1298.

97. Sima, W.; Sun, P.; Yang, M.; Wu, J.; Hua, J. Impact of time parameters of lightning impulse on the breakdown characteristics of oil paper insulation. High Volt. 2016, 1, 18-24. [CrossRef]

98. Chen, H.; Zhang, Y.; Du, Y.; Cheng, Q.S. Comprehensive transient analysis for low-voltage system in a wind turbine under direct lightning. Int. J. Electr. Power Energy Syst. 2020, 121, 106131. [CrossRef]

99. International Electrotechnical Commission. IEC 61400-24 Wind Turbines-Part 24: Lightning Protection. 2010. Available online: file:/ / /C:/Users/MDPI/AppData/Local/Temp/previews_1850287_pre.pdf (accessed on 15 May 2021).

100. Hamel, A.; Gaudreau, A.; Cote, M.; Cables, L.; Côté, M. Intermittent arcing fault on underground low-voltage cables. IEEE Trans. Power Deliv. 2004, 19, 1862-1868. [CrossRef]

101. Aucoin, M. Status of high impedance fault detection. IEEE Trans. Power Appar. Syst. 1985, 3, 637-644. [CrossRef]

102. Wester, C.G. High Impedance Fault Detection on Distribution Systems. In Proceedings of the 1998 Rural Electric Power Conference Presented at 42nd Annual Conference, St. Louis, MO, USA, 26-28 April 1998.

103. Carpenter, M.; Hoad, R.R.; Bruton, T.D.; Das, R.; Kunsman, S.A.; Peterson, J.M. Staged-Fault Testing for High Impedance Fault Data Collection. In Proceedings of the 58th Annual Conference for Protective Relay Engineers, College Station, TX, USA, 5-7 April 2005; IEEE: Piscataway, NJ, USA, 2005; pp. 9-17.

104. Tengdin, J.; Westfall, R.; Stephan, K. High impedance fault detection implementation issues. Rep. PSRC Work. Gr. 1996, 11, 1-4.

105. Masa, A.V.; Maun, J.-C.; Werben, S. Characterization of High Impedance Faults in Solidly Grounded Distribution Networks. In Proceedings of the 17th Power Systems Computation Conference (PSCC), Stockholm, Sweden, 22-26 August 2011.

106. Costa, F.B.; Souza, B.A.; Brito, N.S.D.; Silva, J.A.C.B.; Santos, W.C. Real-time detection of transients induced by high-impedance faults based on the boundary wavelet transform. IEEE Trans. Ind. Appl. 2015, 51, 5312-5323. [CrossRef]

107. Wang, Y.; Zhu, K.; Sun, M.; Deng, Y. An Ensemble Learning Approach for Fault Diagnosis in Self-Organizing Heterogeneous Networks. IEEE Access 2019, 7, 125662-125675. [CrossRef] 
108. Lee, H.; Authority, P.B.C.; Hydro, C.B.C. Development of an Accurate Travelling Wave Fault Locator Using the Global Positioning System Satellites. In Proceedings of the 25th Annual Precise Time and Time Interval Systems and Applications Meeting, Marina Del Rey, CA, USA, 29 November-2 October 1993; pp. 197-204.

109. Mousa, A.M. GPS travelling wave fault locator systems: Investigation into the anomalous measurements related to lightning strikes. IEEE Trans. Power Deliv. 1996, 11, 1214-1223.

110. Rui, L.; Guoqing, F.; Xueyuan, Z.; Xue, X. Fault location based on single terminal travelling wave analysis in radial distribution network. Int. J. Electr. Power Energy Syst. 2015, 66, 160-165.

111. Bo, Z.Q.; Welled, G.; Jiang, F.; Yang, Q.X. Application of GPS Based Fault Location Scheme for Distribution System. In Proceedings of the POWERCON '98: 1998 International Conference on Power System Technology, Beijing, China, 18-21 August 1998; IEEE: Piscataway, NJ, USA, 1998; pp. 53-57.

112. Ghaderi, A.; Mohammadpour, H.A.; Ginn, H. Active Fault Location in Distribution Network Using Time-Frequency Reflectometry. In Proceedings of the 2015 IEEE Power and Energy Conference at Illinois (PECI), Champaign, IL, USA, 20-21 February 2015; IEEE: Piscataway, NJ, USA, 2015; pp. 1-7.

113. Zamora, I.; Miaambres, J.F.; Mazon, A.J. Fault location on two-terminal transmission lines based on voltages. IEEE Proc. Gener. Transm. Distrib. 1996, 143, 1-6. [CrossRef]

114. Doria-Garcia, J.; Orozco-Henao, C.; Iurinic, L.U.; Pulgarín-Rivera, J.D. High impedance fault location: Generalized extension for ground faults. Int. J. Electr. Power Energy Syst. 2020, 114, 105387. [CrossRef]

115. Gadanayak, D.A.; Mallick, R.K. Interharmonics based high impedance fault detection in distribution systems using maximum overlap wavelet packet transform and a modified empirical mode decomposition. Int. J. Electr. Power Energy Syst. 2019, 112, 282-293. [CrossRef]

116. Li, J.; Wang, G.; Zeng, D.; Li, H. High-impedance ground faulted line-section location method for a resonant grounding system based on the zero-sequence current's declining periodic component. Int. J. Electr. Power Energy Syst. 2020, 119, 105910. [CrossRef]

117. Wang, X.; Song, G.; Gao, J.; Wei, X.; Wei, Y.; Mostafa, K.; Hu, Z.; Zhang, Z. High impedance fault detection method based on improved complete ensemble empirical mode decomposition for DC distribution network. Int. J. Electr. Power Energy Syst. 2019, 107, 538-556. [CrossRef]

118. Esmaeilian, A.; Member, S.; Kezunovic, M. An Impedance Based Fault Location Algorithm for Tapped Lines Using Local Measurements. In Proceedings of the 2013 North American Power Symposium (NAPS), Manhattan, KS, USA, 22-24 September 2013; IEEE: Piscataway, NJ, USA, 2013; pp. 1-6.

119. Bi, T.; Lixiao, Y. A Novel Approach to Impedance-Based Fault Location for High Voltage Cables. In Proceedings of the 2012 IEEE Industry Applications Society Annual Meeting, Las Vegas, NV, USA, 7-11 October 2012; IEEE: Piscataway, NJ, USA, 2012; pp. 10-13.

120. Bahmanyar, A. A Practical Integrated Fault Location Method for Electrical Power Distribution Networks. In Proceedings of the 2018 IEEE International Conference on Environment and Electrical Engineering and 2018 IEEE Industrial and Commercial Power Systems Europe (EEEIC/I\&CPS Europe), Palermo, Italy, 12-15 June 2018; pp. 1-5.

121. Majidi, M.; Etezadi-Amoli, M. A New Fault Location Technique in Smart Distribution Networks Using Synchronized/ Nonsynchronized Measurements. IEEE Trans. Power Deliv. 2018, 33, 1358-1368. [CrossRef]

122. Pandakov, K.; Hoidalen, H.K.; Traetteberg, S. An additional criterion for faulty feeder selection during ground faults in compensated distribution networks. IEEE Trans. Power Deliv. 2018, 33, 2930-2937. [CrossRef]

123. Jia, Q.; Dong, X.; Mirsaeidi, S. A traveling-wave-based line protection strategy against single-line-to-ground faults in active distribution networks. Electr. Power Energy Syst. 2019, 107, 403-411. [CrossRef]

124. Liang, R.; Wang, Z.; Peng, N.; Zare, F.; Liu, X.; Liu, C. Traveling wave protection based on asynchronously sampled time difference of arrival of modulus traveling waves in per unit line length. Electr. Power Syst. Res. 2018, 165, 250-258. [CrossRef]

125. Aoyu, L.; Dong, X.; Shi, S.; Bin, W. A Novel Current Travelling Wave Based Single-Ended Fault Location Method for Locating Single-Phase-to-Ground Fault of Transmission Line. In Proceedings of the 2015 50th International Universities Power Engineering Conference (UPEC), Stroke-on-Trent, UK, 1-4 September 2015; IEEE: Piscataway, NJ, USA, 2015; pp. 1-6.

126. Khokhar, S.; Asuhaimi, A.; Zin, B.M.; Safawi, A.; Mokhtar, B.; Pesaran, M. A comprehensive overview on signal processing and artificial intelligence techniques applications in classification of power quality disturbances. Renew. Sustain. Energy Rev. 2015, 51, 1650-1663. [CrossRef]

127. Tonello, A.M.; Letizia, N.A.; Righini, D.; Marcuzzi, F. Machine Learning Tips and Tricks for Power Line Communications. IEEE Access 2019, 7, 82434-82452. [CrossRef]

128. Apisit, C.; Pothisarn, C.; Ngaopitakkul, A. An Application of Discrete Wavelet Transform and Support Vector Machines Algorithm for Fault Locations in Underground Cable. In Proceedings of the 2012 Third International Conference on Innovations in BioInspired Computing and Applications, Kaohsiung, Taiwan, 26-28 September 2012; pp. 89-92.

129. Rafinia, A.; Moshtagh, J. A new approach to fault location in three-phase underground distribution system using combination of wavelet analysis with ANN and FLS Ali. Int. J. Electr. Power Energy Syst. 2014, 55, 261-274. [CrossRef]

130. Adewole, A.C.; Tzoneva, R.; Behardien, S. Distribution network fault section identification and fault location using wavelet entropy and neural networks. Appl. Soft Comput. J. 2016, 46, 296-306. [CrossRef]

131. Yang, Q.; Le Blond, S.; Aggarwal, R.; Wang, Y.; Li, J. New ANN method for multi-terminal HVDC protection relaying. Electr. Power Syst. Res. 2017, 148, 192-201. [CrossRef] 
132. Hassan, Z.; Amir, A.; Selvaraj, J.; Rahim, N.A. A review on current injection techniques for low-voltage ride-through and grid fault conditions in grid-connected photovoltaic system. Sol. Energy 2020, 207, 851-873. [CrossRef]

133. Tu, J.V. Advantages and disadvantages of using artificial neural networks versus logistic regression for predicting medical outcomes. J. Clin. Epidemiol. 1996, 49, 1225-1231. [CrossRef]

134. Le Blond, S.; Aggarwal, R. A Review of Artificial Intelligence Techniques as Applied to Adaptive Autoreclosure, with Particular Reference to Deployment with Wind Generation. In Proceedings of the 2009 44th International Universities Power Engineering Conference (UPEC), Glasgow, UK, 1-4 September 2009; pp. 1-5.

135. He, Z.; Shao, H.; Zhong, X.; Zhao, X. Ensemble transfer CNNs driven by multi-channel signals for fault diagnosis of rotating machinery cross working conditions. Knowl.-Based Syst. 2020, 207, 106396. [CrossRef]

136. Plakias, S.; Boutalis, Y.S. Fault detection and identification of rolling element bearings with Attentive Dense CNN. Neurocomputing 2020, 405, 208-217. [CrossRef]

137. Rai, P.; Londhe, N.D.; Raj, R. Fault classification in power system distribution network integrated with distributed generators using CNN. Electr. Power Syst. Res. 2021, 192, 106914. [CrossRef]

138. Lei, X.; Sui, Z. Intelligent fault detection of high voltage line based on the Faster R-CNN. Meas. J. Int. Meas. Confed. 2019, 138, 379-385. [CrossRef]

139. Veerasamy, V.; Wahab, N.I.A.; Othman, M.L.; Padmanaban, S.; Sekar, K.; Ramachandran, R.; Hizam, H.; Vinayagam, A.; Islam, M.Z. LSTM Recurrent Neural Network Classifier for High Impedance Fault Detection in Solar PV Integrated Power System. IEEE Access 2021, 9, 32672-32687. [CrossRef]

140. Xiang, L.; Wang, P.; Yang, X.; Hu, A.; Su, H. Fault detection of wind turbine based on SCADA data analysis using CNN and LSTM with attention mechanism. Meas. J. Int. Meas. Confed. 2021, 175, 109094. [CrossRef]

141. Belagoune, S.; Bali, N.; Bakdi, A.; Baadji, B.; Atif, K. Deep learning through LSTM classification and regression for transmission line fault detection, diagnosis and location in large-scale multi-machine power systems. Measurement 2021, 177, 109330. [CrossRef]

142. Khan, E.; Venkatapuram, P. Neufuz: Neural Network Based Fuzzy Logic Design Algorithms. In Proceedings of the 1993 Second IEEE International Conference on Fuzzy Systems, San Francisco, CA, USA, 28 March-1 April 1993; pp. 1-8.

143. Dash, P.K.; Padhee, M.; Panigrahi, T.K. A hybrid time-frequency approach based fuzzy logic system for power island detection in grid connected distributed generation. Int. J. Electr. Power Energy Syst. 2012, 42, 453-464. [CrossRef]

144. Jung, C.K.; Kim, K.H.; Lee, J.B.; Klöckl, B. Wavelet and neuro-fuzzy based fault location for combined transmission systems. Int. J. Electr. Power Energy Syst. 2007, 29, 445-454. [CrossRef]

145. Goli, R.K.; Gafoor Shaik, A.; Tulasi Ram, S.S. A transient current based double line transmission system protection using fuzzy-wavelet approach in the presence of UPFC. Int. J. Electr. Power Energy Syst. 2015, 70, 91-98. [CrossRef]

146. Bejmert, D.; Rebizant, W.; Schiel, L. Transformer differential protection with fuzzy logic based inrush stabilization. Int. J. Electr. Power Energy Syst. 2014, 63, 51-63. [CrossRef]

147. Calderon-Mendoza, E.; Schweitzer, P.; Weber, S. Kalman filter and a fuzzy logic processor for series arcing fault detection in a home electrical network. Int. J. Electr. Power Energy Syst. 2019, 107, 251-263. [CrossRef]

148. Palfi, J.; Takacs, M.; Hocsik, P.; Mitrik, Z. Determination of the Fault Identification Accuracy in L V Networks Using the Fuzzy Method. In Proceedings of the 2016 IEEE International Conference on Systems, Man, and Cybernetics (SMC), Budapest, Hungary, 9-12 October 2016; pp. 2756-2761.

149. Yadav, A.; Swetapadma, A. Enhancing the performance of transmission line directional relaying, fault classification and fault location schemes using fuzzy inference system. IET Gener. Transm. Distrib. 2015, 9, 580-591. [CrossRef]

150. Dhimish, M.; Holmes, V.; Mehrdadi, B.; Dales, M. Comparing Mamdani Sugeno fuzzy logic and RBF ANN network for PV fault detection. Renew. Energy 2018, 117, 257-274. [CrossRef]

151. Mustafa, M.; EI-Khattam, W.; Galal, Y. A Novel Fuzzy Cause-and-Effect-Networks Based Methodology for a Distribution System's Fault Diagnosis. In Proceedings of the 2013 3rd International Conference on Electric Power and Energy Conversion Systems, Istanbul, Turkey, 2-4 October 2013.

152. Bellanco, I.; Fuentes, E.; Vallès, M.; Salom, J. A review of the fault behavior of heat pumps and measurements, detection and diagnosis methods including virtual sensors. J. Build. Eng. 2021, 39, 102254. [CrossRef]

153. Smola, A.J.; Scholkopf, B. A Tutorial on Support Vector Regression. Stat. Comput. 2003, 12, 17-35. [CrossRef]

154. Deng, X.; Yuan, R.; Xiao, Z.; Li, T.; Wang, K.L.L. Fault location in loop distribution network using SVM technology. Int. J. Electr. Power Energy Syst. 2015, 65, 254-261. [CrossRef]

155. Ray, P.; Mishra, D.P.; Panda, D.D. Hybrid Technique for Fault Location of a Distribution Line. In Proceedings of the 2015 Annual IEEE India Conference (INDICON), New Delhi, India, 17-20 December 2015; pp. 1-6.

156. Bacha, K.; Salem, S.B.; Chaari, A. An improved combination of Hilbert and Park transforms for fault detection and identification in three-phase induction motors. Int. J. Electr. Power Energy Syst. 2012, 43, 1006-1016. [CrossRef]

157. Swetapadma, A.; Yadav, A. Directional relaying using support vector machine for double circuit transmission lines including cross-country and inter-circuit faults. Int. J. Electr. Power Energy Syst. 2016, 81, 254-264. [CrossRef]

158. Dalei, J.; Mohanty, K.B. Fault classification in SEIG system using Hilbert-Huang transform and least square support vector machine. Int. J. Electr. Power Energy Syst. 2016, 76, 11-22. [CrossRef]

159. Chuan, O.W.; Ab Aziz, N.F.; Yasin, Z.M.; Salim, N.A.; Wahab, N.A. Fault classification in smart distribution network using support vector machine. Indones. J. Electr. Eng. Comput. Sci. 2020, 18, 1148-1155. [CrossRef] 
160. Sahri, Z.B.; Yusof, R.B. Support Vector Machine-Based Fault Diagnosis of Power Transformer Using k Nearest-Neighbor Imputed DGA Dataset. J. Comput. Commun. 2014, 02, 22-31. [CrossRef]

161. Gu, Y.; Zeng, X.; Xu, S.; Deng, S. IMF Energy Moments and LS-SVM Based Fault Section Location Method for Distribution Network. In Proceedings of the 2015 5th International Conference on Electric Utility Deregulation and Restructuring and Power Technologies (DRPT), Changsha, China, 26-29 November, 2015; pp. 1206-1213.

162. Geramian, S.S.; Abyane, H.A.; Mazlumi, K. Determination of Optimal PMU Placement for Fault Location Using Genetic Algorithm. In Proceedings of the 2008 13th International Conference on Harmonics and Quality of Power, Wollongong, NSW, Australia, 28 September-1 October 2008; IEEE: Piscataway, NJ, USA, 2008; pp. 1-5.

163. Yue, Y.; Wang, H. A Study of Distribution Network Fault Location Including Distributed Generator Based on Improved Genetic Algorithm. In Proceedings of the 2012 3rd International Conference on System Science, Engineering Design and Manufacturing Informatization, Chengdu, China, 20-21 October 2012; pp. 103-106.

164. Hua, L.; Baoqun, Z.; Hong, Z. Recognition and Classification of Power Quality Event in Power System Using Wavelet Transformation. In Proceedings of the 2008 27th Chinese Control Conference, Kunming, China, 16-18 July 2008; pp. 43-46.

165. Gengyin, L.I.; Ming, Z.; Zhiyuan, Z. Power Quality Disturbance Automatic Recognition. In Proceedings of the 2002 IEEE Region 10 Conference on Computers, Communications, Control and Power Engineering. TENCOM'02. Proceedings, Beijing, China, 28-31 October 2002; pp. 1923-1926.

166. Huang, C.L.; Li, T.S.; Peng, T.K. A hybrid approach of rough set theory and genetic algorithm for fault diagnosis. Int. J. Adv. Manuf. Technol. 2005, 27, 119-127. [CrossRef]

167. Kamrani, A.; Rong, W.; Gonzalez, R. A genetic algorithm methodology for data mining and intelligent knowledge acquisition. Comput. Ind. Eng. 2001, 40,361-377. [CrossRef]

168. Moloi, K.; Yusuff, A.A. Power Distribution System Fault Diagnostic Using Genetic Algorithm and Neural Network. In Proceedings of the 2021 Southern African Universities Power Engineering Conference/Robotics and Mechatronics/Pattern Recognition Association of South Africa (SAUPEC/RobMech/PRASA), Potchefstroom, South Africa, 27-29 January 2021; pp. 6-10.

169. Mirnaghi, M.S.; Haghighat, F. Fault detection and diagnosis of large-scale HVAC systems in buildings using data-driven methods: A comprehensive review. Energy Build. 2020, 229, 110492. [CrossRef]

170. Wang, J.; Li, S.; An, Z.; Jiang, X.; Qian, W.; Ji, S. Batch-normalized deep neural networks for achieving fast intelligent fault diagnosis of machines. Neurocomputing 2019, 329, 53-65. [CrossRef]

171. Li, B.; Delpha, C.; Diallo, D.; Migan-Dubois, A. Application of Artificial Neural Networks to photovoltaic fault detection and diagnosis: A review. Renew. Sustain. Energy Rev. 2021, 138, 110512. [CrossRef]

172. Germán-Salló, Z.; Strnad, G. Signal processing methods in fault detection in manufacturing systems. Procedia Manuf. 2018, 22, 613-620. [CrossRef]

173. Zhang, L.; Frank, S.; Kim, J.; Jin, X.; Leach, M. A systematic feature extraction and selection framework for data-driven whole-building automated fault detection and diagnostics in commercial buildings. Build. Environ. 2020, 186, 107338. [CrossRef]

174. Robertson, D.C.; Camps, O.I.; Mayer, J.S.; Gish, W.B. Wavelets and electromagnetic power system transients. IEEE Trans. Power Deliv. 1996, 11, 1050-1056. [CrossRef]

175. Sabug, L.; Musa, A.; Costa, F.; Monti, A. Real-time boundary wavelet transform-based DC fault protection system for MTDC grids. Int. J. Electr. Power Energy Syst. 2020, 115, 105475. [CrossRef]

176. Shaik, A.G.; Pulipaka, R.R.V. A new wavelet based fault detection, classification and location in transmission lines. Int. J. Electr. Power Energy Syst. 2015, 64, 35-40. [CrossRef]

177. Dehghani, M.; Khooban, M.H.; Niknam, T. Fast fault detection and classification based on a combination of wavelet singular entropy theory and fuzzy logic in distribution lines in the presence of distributed generations. Int. J. Electr. Power Energy Syst. 2016, 78, 455-462. [CrossRef]

178. Marques da Silva, D.; Costa, F.B.; Miranda, V.; Leite, H. Wavelet-based analysis and detection of traveling waves due to DC faults in LCC HVDC systems. Int. J. Electr. Power Energy Syst. 2019, 104, 291-300. [CrossRef]

179. Sharma, P.; Saini, D.; Saxena, A. Fault Detection and Classification in Transmission Line Using Wavelet Transform and ANN. Bull. Electr. Eng. Inform. 2016, 5, 456-465.

180. Devi, S.; Swarnkar, N.K.; Ola, S.R.; Mahela, O.P. Detection of Transmission Line Faults Using Discrete Wavelet Transform. In Proceedings of the 2016 Conference on Advances in Signal Processing (CASP), Pune, India, 9-11 June 2016; pp. 133-138.

181. Mishra, R.C.; Deoghare, P.M.; Bhale, C.; Lanjewar, S. Wavelet Based Transmission Line Fault Classification And Location. In Proceedings of the 2014 International Conference on Smart Electric Grid (ISEG), Guntur, India, 19-20 September 2014; pp. 1-5.

182. Choudary, S.; Mahela, O.P.; Ola, S.R. Detection of Transmission Line Faults in the Presence of Thyristor Switched Capacitor Using Discrete Wavelet Transform. In Proceedings of the 2016 IEEE 7th Power India International Conference (PIICON), Bikaner, India, 25-27 November 2016; pp. 4-8.

183. Magagula, X.G.; Hamam, Y.; Jordaan, J.A. A Fault Classification and Localization Method in A Power Distribution Network. In Proceedings of the 2017 IEEE AFRICON, Cape Town, South Africa, 18-20 September 2017; pp. 1385-1391.

184. Kamthekar, P.R. Detection and Classification of Power Quality Events using DWT and MSD. In Proceedings of the 2017 International Conference on Innovative Mechanisms for Industry Applications (ICIMIA), Bengaluru, India, 24-25 February 2017; pp. 150-157. 
185. Upadhyaya, S.; Mohanty, S. Power Quality disturbance detection using Wavelet based signal processing. In Proceedings of the 2013 Annual IEEE India Conference (INDICON), Mumbai, India, 13-15 December 2013; IEEE: Piscataway, NJ, USA, 2013; pp. 1-6.

186. Sugi, R. Estimation of Power Quality Indices Using Discrete Wavelet Transform. In Proceedings of the 2016 3rd International Conference on Advanced Computing and Communication Systems (ICACCS), Coimbatore, India, 22-23 January 2016.

187. Chen, Y.; Zhang, T.; Luo, Z.; Sun, K. A novel rolling bearing fault diagnosis and severity analysis method. Appl. Sci. 2019, 9, 2356. [CrossRef]

188. Mohanty, S.R.; Kishor, N.; Ray, P.K.; Catalao, J.P.S. Comparative study of advanced signal processing techniques for islanding detection in a hybrid distributed generation system. IEEE Trans. Sustain. Energy 2015, 6, 122-131. [CrossRef]

189. Ashrafian, A.; Mirsalim, M. On-line recursive method of phasor and frequency estimation for power system monitoring and relaying. IET Gener. Transm. Distrib. 2016, 10, 2002-2011. [CrossRef]

190. Xi, C.; Chen, Q.; Wang, L. A Single-Terminal Traveling Wave Fault Location Method for VSC-HVDC Transmission Lines Based on S-Transform. In Proceedings of the 2016 IEEE PES Asia-Pacific Power and Energy Engineering Conference (APPEEC), Xi'an, China, 25-28 October 2016; pp. 1008-1012.

191. Shang, L.; Zhai, W.; Liu, P. Study of fault location in transmission line using S transform. Int. Symp. Comput. Consum. Control 2016, 1, 85-88.

192. Farshad, M.; Sadeh, J. Generalized instance-based fault locating in transmission lines using single-ended voltage measurements. Int. Trans. Electr. Energy Syst. 2015, 25, 799-816. [CrossRef]

193. Prasad, D.; Papia, M. Fault Detection, Location and Classification of a Transmission Line; Springer: London, UK, 2018; Volume 30, ISBN 0123456789.

194. Roy, N.; Bhattacharya, K. Detection, classification, and estimation of fault location on an overhead transmission line using S-transform and neural network. Electr. Power Components Syst. 2015, 43, 461-472. [CrossRef]

195. Lima, E.M.; Coelho, R.D.A.; Silva, N.; Brito, D.; Souza, B.A. De High Impedance Fault Detection Based on Stockwell Transform. In Proceedings of the 2018 IEEE PES Transmission \& Distribution Conference and Exhibition-Latin America (T\&D-LA), Lima, Perú, 18-21 September 2018; pp. 1-5.

196. Agarwal, N.; Mahela, O.P.; Kumar, B. Detection of Transmission Line Faults in the Presence of Dynamic Load Using Stockwell's Transform. In Proceedings of the 2016 IEEE 7th Power India International Conference (PIICON), Bikaner, India, 25-27 November 2016; pp. 1-6.

197. Bharata, M.J.; Gopakumar, P.; Mohanta, D.K. A novel transmission line protection using DOST and SVM. Eng. Sci. Technol. Int. J. 2016, 19, 1027-1039.

198. Jiao, S.-B.; Yang, Y.-P.; Shi, Y.-J.; Shi, W.-W. Fast S-Transform for fault line selection in distribution network system. In Proceedings of the 2018 13th IEEE Conference on Industrial Electronics and Applications (ICIEA), Wuhan, China, 31 May-2 June 2018.

199. Moravej, Z.; Member, S.; Pazoki, M.; Khederzadeh, M.; Member, S. New pattern-recognition method for fault analysis in transmission line with UPFC. IEEE Trans. Power Deliv. 2015, 30, 1231-1242. [CrossRef]

200. Patel, B. A new FDOST entropy based intelligent digital relaying for detection, classification and localization of faults on the hybrid transmission line. Electr. Power Syst. Res. 2018, 157, 39-47. [CrossRef]

201. Shukla, S.; Mishra, S.; Singh, B. Empirical-mode decomposition with hilbert transform for power-quality assessment. IEEE Trans. Power Deliv. 2009, 24, 2159-2165. [CrossRef]

202. Huang, N.E.; Shen, Z.; Long, S.R.; Wu, M.C.; Shih, H.H.; Yen, N.; Tung, C.C.; Liu, H.H. The empirical mode decomposition and the Hilbert spectrum for nonlinear and non-stationary time series analysis. R. Soc. London Proc. Ser. A 1996, 454, 903-995. [CrossRef]

203. Rehm, S.J.; Yoon, F.C.; Longworth, D.L. Clinical events and laboratory abnormalities in patients receiving home intravenous antibiotic therapy (HIVAT). Clin. Infect. Dis. 1997, 25, 426.

204. Ramesh Babu, N.; Jagan Mohan, B. Fault classification in power systems using EMD and SVM. Ain Shams Eng. J. 2017, 8, 103-111. [CrossRef]

205. Singh, D.S.; Zhao, Q. Pseudo-fault signal assisted EMD for fault detection and isolation in rotating machines. Mech. Syst. Signal Process. 2016, 81, 202-218. [CrossRef]

206. Xiao, M.; Zhang, C.; Wen, K.; Xiong, L.; Geng, G.; Wu, D. Bearing fault feature extraction method based on complete ensemble empirical mode decomposition with adaptive noise. J. Vibroeng. 2018, 20, 2622-2631. [CrossRef]

207. Li, H.; Liu, T.; Wu, X.; Chen, Q. Application of EEMD and improved frequency band entropy in bearing fault feature extraction. ISA Trans. 2019, 88, 170-185. [CrossRef] [PubMed]

208. Zheng, K.; Luo, J.; Zhang, Y.; Li, T.; Wen, J.; Xiao, H. Incipient fault detection of rolling bearing using maximum autocorrelation impulse harmonic to noise deconvolution and parameter optimized fast EEMD. ISA Trans. 2018, 89, 256-271. [CrossRef] [PubMed]

209. Wang, X.; Gao, J.; Wei, X.; Zeng, Z.; Wei, Y.; Kheshti, M. Single Line to Ground Fault Detection in a Non-Effectively Grounded Distribution Network. IEEE Trans. Power Deliv. 2018, 33, 3173-3186. [CrossRef]

210. Gnativ, R.; Milanovi, J.V. Voltage Sag Propagation In Systems With Embedded Generation And Induction Motors. In Proceedings of the 2001 Power Engineering Society Summer Meeting. Conference Proceedings, Vancouver, BC, Canada, 15-19 July 2001; pp. 474-479. 
211. Mustapa, R.F.; Serwan, M.S.; Hamzah, N.; Zakaria, Z. Hypothesis Testing for Fault Analysis and the Propagation of Faulted Voltage through Transformer Connections. In Proceedings of the 2011 IEEE Student Conference on Research and Development, Cyberjaya, Malaysia, 19-20 December 2011; pp. 215-220.

212. Xiaowei, W.; Xiangxiang, W.; Dechang, Y.; Guobing, S.; Jie, G.; Yanfang, W. Fault feeder detection method utilized steady state and transient components based on FFT backstepping in distribution networks. Electr. Power Energy Syst. 2020, 114,105391 [CrossRef]

213. Xue, T.; Ding, S.X.; Zhong, M.; Li, L. A distribution independent data-driven design scheme of optimal dynamic fault detection systems. J. Process Control 2020, 95, 1-9. [CrossRef]

214. Greber, M.; Fodor, A.; Magyar, A. Generalized persistent fault detection in distribution systems using network flow distribution systems using network flow General. IFAC Pap. 2020, 53, 13568-13574. [CrossRef]

215. Kaur, G. Power Generation Firms to Face More Competition. Available online: https://www.thestar.com.my/business/businessnews/2020/01/10/power-generation-firms-to-face-more-competition (accessed on 15 May 2021).

216. Zainuddin, A. Can Malaysia Adapt to and Embrace Efficient Power Generation? Available online: https://themalaysianreserve. com/2017/09/21/can-malaysia-adapt-embrace-efficient-power-generation/ (accessed on 23 March 2021).

217. Mung, T.S. Renewable Energy Players Rise after Winning Bids for LSS4. Available online: https://www.theedgemarkets.com/ article/renewable-energy-players-rise-after-winning-bids-1ss4\#: \{\}:text=KUALA\%20LUMPUR\%20(March\%2015)\%3A,sen\% 20or\%201.07\%25\%20to\%20RM2 (accessed on 23 March 2021).

218. Lee, J.Y.; Verayiah, R.; Ong, K.H.; Ramasamy, A.K.; Marsadek, M.B. Distributed Generation: A Review on Current Energy Status, Grid-Interconnected PQ Issues, and Implementation Constraints of DG in Malaysia. Energies 2020, 13, 6479. [CrossRef]

219. Boutasseta, N.; Ramdani, M.; Mekhilef, S. Fault-tolerant power extraction strategy for photovoltaic energy systems. Sol. Energy 2018, 169, 594-606. [CrossRef]

220. Feng, X.; Xiong, Q.; Wardell, D.; Gattozzi, A.L.; Strank, S.M.; Hebner, R.E. Extra-Fast DC distribution system protection for future energy systems. IEEE Trans. Ind. Appl. 2019, 55, 3421-3430. [CrossRef]

221. Rahman, F.A.A.; Kadir, M.Z.A.A.; Osman, M.; Amirulddin, U.A.U. Review of the AC Overhead Wires, the DC Third Rail and the DC Fourth Rail Transit Lines: Issues and Challenges. IEEE Access 2020, 8, 213277-213295. [CrossRef]

222. Aodsup, K.; Kulworawanichpong, T. Lightning Surge Propagation Analysis in OHGW of Electrified High Speed Railway. Energy Procedia 2017, 138, 99-104. [CrossRef]

223. Hajikhani, M.; Ab-Kadir, M.Z.A.; Izadi, M.; Gomes, C.; Jasni, J. A Comparison of Lightning Human Fatalities between Malaysia and United States. In Proceedings of the 2016 33rd International Conference on Lightning Protection (ICLP), Estoril, Portugal, 25-30 September 2016; IEEE: Piscataway, NJ, USA, 2016; pp. 1-5.

224. Ahmad, S.; Zainal, M.; Ab, A.; Shafie, S. Current perspective of the renewable energy development in Malaysia. Renew. Sustain. Energy Rev. 2011, 15, 897-904. [CrossRef]

225. Hajikhani, M.; Ab-Kadir, M.Z.A.; Izadi, M.; Gomes, C.; Jasni, J. Lightning Fatalities and Injuries in Malaysia from 2008 to 2015. In Proceedings of the 2016 33rd International Conference on Lightning Protection (ICLP), Estoril, Portugal, 25-30 September 2016; IEEE: Piscataway, NJ, USA, 2016; pp. 1-6.

226. Ab Kadir, M.Z.A.; Misbah, N.R.; Gomes, C.; Jasni, J.; Wan Ahmad, W.F.; Hassan, M.K. Recent Statistics on Lightning Fatalities in Malaysia. In Proceedings of the 2012 International Conference on Lightning Protection (ICLP), Estoril, Portugal, 25-30 September 2016; IEEE: Piscataway, NJ, USA, 2012; pp. 1-5.

227. Rui, L.; Nan, P.; Zhi, Y.; Zare, F. A novel single-phase-to-earth fault location method for distribution network based on zerosequence components distribution characteristics. Int. J. Electr. Power Energy Syst. 2018, 102, 11-22. [CrossRef]

228. Davoudi, M.G.; Sadeh, J.; Kamyab, E. Time Domain Fault Location on Transmission Lines Using Genetic Algorithm. In Proceedings of the 2012 11th International Conference on Environment and Electrical Engineering, Venice, Italy, 18-25 May 2012; pp. 1087-1092.

229. Jamali, S.; Bahmanyar, A.; Borhani-Bahabadi, H. A Fast and Accurate Fault Location Method for Distribution Networks with dg Using Genetic Algorithms; IEEE: Piscataway, NJ, USA, 2015; pp. 110-114.

230. Ahmed, A.S.; Attia, M.A.; Hamed, N.M.; Abdelaziz, A.Y. Comparison between Genetic Algorithm and Whale Optimization Algorithm in Fault Location Estimation in Power Systems. In Proceedings of the 2017 Nineteenth International Middle East Power Systems Conference, Shibin el Kom, Egypt, 19-21 December 2017; pp. 631-637.

231. Ibrahim, M.S.; Dong, W.; Yang, Q. Machine learning driven smart electric power systems: Current trends and new perspectives. Appl. Energy 2020, 272, 115237. [CrossRef]

232. Sobrinho, A.S.F.; Junior, F.G. Type-1 fuzzy logic algorithm for low cost embedded systems. Comput. Electr. Eng. 2020, 88, 1-14. [CrossRef] 